Linköping Studies in Science and Technology

Dissertation No. 1987

\title{
Surface \\ Characterization \\ and Manipulation \\ of Polyampholytic \\ Hydrogel Coatings
}

Feng-I Tai

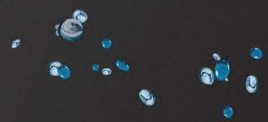

$+$

$+\therefore$

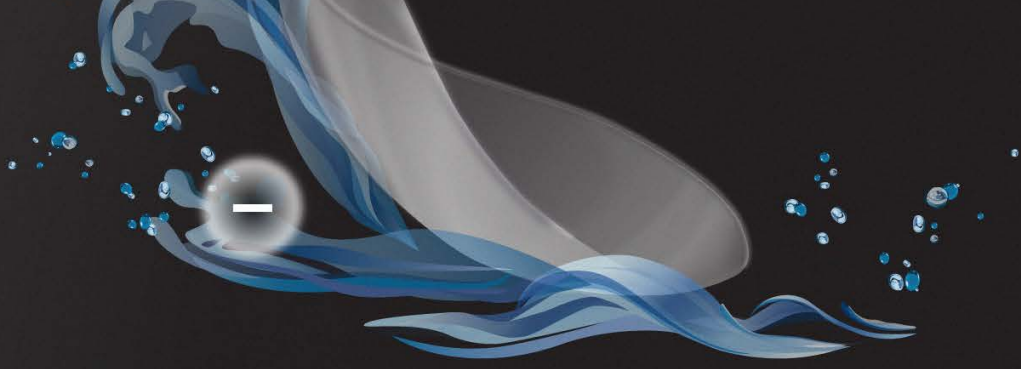

LINKÖPING

UNIVERSITY 
Linköping Studies in Science and Technology

Dissertation No. 1987

Surface Characterization and Manipulation of Polyampholytic Hydrogel Coatings

\author{
Feng-I Tai
}

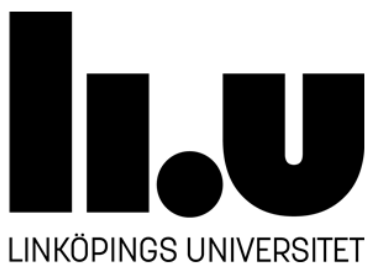

Division of Molecular Physics, Department of Physics, Chemistry and Biology

Linköpings Universitet

SE-581 83 Linköping, Sweden

Linköping 2019 


\section{Surface Characterization and Manipulation of Polyampholytic Hydrogel Coatings \\ Feng-I Tai \\ ISBN 978-91-7685-083-1 \\ ISSN 0345-7524}

(c) Copyright 2019 Feng-I Tai, unless otherwise mentioned

Linköping studies in science and technology. Dissertations, No. 1987

Department of Physics, Chemistry and Biology

Linköpings Universitet

SE-581 83 Linköping

Sweden

During the course of the research presented in this thesis, Feng-I Tai, was enrolled in Forum Scientium, a multidisciplinary graduate school at Linköping University, Sweden.

Cover:

An ideal polyampholytic hydrogel coating at charge-balanced condition, with minimized electrostatic interactions with approaching objects.

Typeset in $\mathrm{IT}_{\mathrm{E}} \mathrm{X}$. Figures created using Adobe Illustrator CC 2019, OriginLab Origin 9.1, and WSxM 5.0 Develop

Electronic publication: http://www.ep.liu.se

Printed by LiU-Tryck

Linköping, Sweden 2019 
To Yuan-Chih 



\title{
Surface Characterization and Manipulation of Polyampholytic Hydrogel Coatings
}

Feng-I Tai

Department of Physics, Chemistry and Biology

Linköping University

\begin{abstract}
This thesis is dedicated to building up fundamental knowledge about polyampholytic hydrogels, which are developed in our group for anti-fouling purposes. Charge-balanced polymers, where positive and negative charges balance each other, have emerged as interesting candidates for many applications in materials science. We have prepared charge-balanced materials by forming thickness gradients of oppositely charged polyelectrolytes, and use these as model systems for a systematic investigation of the materials and their responses to environmental changes. These hydrogel gradients were sequentially grafted from substrates via surface-initiated photografting and photopolymerization (SIPGP) of cationic and anionic polyelectrolytes. At some thickness ratios, these form a charge-balanced system where the net surface charge is zero, and with certain similarity to zwitterionic systems. The surface charge of the hydrogels is the principal parameter regulating non-specific protein adsorption, and among other things, we demonstrate that the position of the fouling-resistant charge-neutral region can be manipulated upon $\mathrm{pH}$ changes. The chemical compositions of the hydrogel gradients were characterized by microscopic infrared spectroscopy. Optical analysis by spectroscopic ellipsometry and imaging surface plasmon resonance were used to monitor the swelling of the hydrogel films, and protein adsorption onto these in real-time. Surface forces, i.e. the interactions with the hydrogels from an intermolecular perspective, which are related mainly to electrostatic and steric forces, were probed by direct force measurement using atomic force microscopy. Force curves were used to determine the surface charge distribution over the hydrogels, and to indicate the correlation between surface charge and protein adsorption. In the later work, hydrogel gradients were patterned as arrayed spots. Their thicknesses and surface roughness provide further information about the polymer structure and provides a basis for
\end{abstract}


relating ellipsometric swelling profiles to thicknesses as obtained by atomic force microscopy. Finally, it is demonstrated how charged hydrogel films can be used as spacers to tune the optimum distance between silver nanoparticles and fluorophores for metal-enhanced fluorescence (MEF).

The aim of this work is to understand polyampholytic hydrogels from various perspectives: surface charges and their distribution, the polymer structure, and surface interactions. The knowledge and experience obtained contribute to the general understanding of zwitterionic materials, and to the development of anti-fouling coatings, optical sensing platforms and other applications of charge-balanced hydrogels.

Keywords: Hydrogels, antifouling, charge-balanced material, polyampholytes, force measurements, polymer swelling, protein adsorption, patterning, plasmonics 


\section{Populärvetenskaplig sammanfattning}

Arbetet i denna avhandling syftar till att bidra med kunskaper för att skapa bättre ytbeläggningar för påväxthindrande ändamål. Det finns många miljöer där biologiskt material som fäster på ytor kan skapa problem, till exempel inflammatoriska reaktioner i biomedicinska tillämpningar, bakteriefilmer i livsmedels- och processindustri, och marina tillämpningar. Ytbeläggning som skydd eller dekoration har en lång historia i den mänskliga civilisationen, exempelvis som färg på trä, plätering på metaller, och glasyr på keramik. Genom att låta ett tunt skikt ha egenskaper som skyddar från påverkan från omgivningen, kan man effektivt skydda det underliggande materialet från skador orsakade av exempelvis förruttnelse, rost, eller sprickor, men även ge estetiska förbättringar.

Inom biomedicin är det önskvärt att skapa ytor och material som inte reagerar i kontakt med kroppsvätskor, och på så sätt skadar vävnad eller orsakar oönskade immunreaktioner. Dessa material eller beläggningar måste på ett effektivt sätt förhindra adsorption av proteiner och andra makromolekyler, på ett sätt som inte skadar kroppen. I marina miljöer fäster vattenlevande organismer som havstulpaner, alger och musslor på ytor under vatten, och bildar ekosystem, vilka till exempel ökar bränsleförbrukningen och orsakar skador på fartyg. Påväxthindrande färger har använts i stor omfattning för att förhindra sådan påväxt, och har under lång tid har dessa innehållit gifter, ofta tenn- eller kopparföreningar, som har visat sig vara skadliga för miljön och vattenlevande organismer långt bortom de ytor där de har applicerats. Krav på minskad användning av toxiner och minimering av miljörisker har skapat en efterfrågan på giftfria färger, och ytbeläggningar som är både kostnadseffektiva och miljövänliga. Få lämpliga alternativ till giftiga färger finns tillgängliga idag, och generella lösningar saknas. Detta ställer nya krav på kunskaper om både de organismer som fäster på ytor och på tänkbara material, och har även resulterat i bättre samordning med ansträngningarna att skapa påväxthindrande material för biomedicinska tillämpningar.

I denna avhandling studeras tunna skikt av hydrogeler, och grundläggande egenskaper hos dessa som är relevanta för att förhindra påväxt eller oönskad adsorption av biologiskt material. Hydrogeler är en klass av polymerer som karakteriseras av förmågan att kunna ta upp stora mängder vatten, och genom att styra polymerens sammansättning eller omgivningens egenskaper kan dess svällning kontrolleras. Många hydrogeler används i biomedicinska tillämpningar, och ett utmärkt 
exempel är mjuka kontaktlinser. De hydrogeler som använts i denna avhandling är elektriskt laddade, och när de positiva och negativa laddningarna i hydrogelen balanserar varandra, uppvisar de mycket god resistens mot inbindning av biomolekyler och annat biologiskt material. Att förhindra adsorption av proteiner och andra biomakromolekyler är viktigt för biomedicinska tillämpningar, och även ett första steg i fortsatt påväxt av makroorganismer i marina miljöer. I detta arbete har olika elektriskt laddade hydrogeler används som modellsystem för att förstå hur de fungerar i olika kemiska miljöer, och hur de kan manipuleras för att skapa funktionella ytbeläggningar vars egenskaper kan ändras eller påverkas genom ändrade kemiska förutsättningar som påverkar balansen mellan motsatta laddningar. Det långsiktiga målet är att förbättra den grundläggande förståelsen för laddningsbalanserade material, och hur dessa kan användas för att skapa påväxthindrande ytbeläggningar. 


\section{List of publications}

This thesis includes the following papers:

I Lateral Control of Protein Adsorption on Charged Polymer Gradients

Tobias Ekblad, Olof Andersson, Feng-I Tai, Thomas Ederth and Bo Liedberg

Langmuir, 2009, 25, 3755-3762

doi: $10.1021 /$ la $803443 \mathrm{~d}$

II pH-Control of the Protein Resistance of Thin Hydrogel Gradient Films

Feng-I Tai, Olof Sterner, Olof Andersson, Tobias Ekblad and Thomas Ederth

Soft Matter, 2014, 10, 5955-5964

doi: $10.1039 / \mathrm{c} 4 \mathrm{sm} 00833 \mathrm{~b}$

III Interaction Forces on Polyampholytic Hydrogel Gradient Surfaces

Feng-I Tai, Olof Sterner, Olof Andersson, Tobias Ekblad and Thomas Ederth

ACS Omega, 2019, 4, 5670-5681

doi: 10.1021/acsomega.9b00339

IV Spot-Patterned Hydrogel Gradients

Feng-I Tai, Olof Sterner and Thomas Ederth

In manuscript

V Hydrogel Films as Spacers for Optimization of Metal Enhanced Fluorescence

Feng-I Tai, Daniel Sjölander, Erik Martinsson and Daniel Aili

In manuscript

The author's contributions to the papers:

I Direct force measurements experimental, data analysis and result discussion written in the manuscript.

II Planning and carrying out the direct force measurements and Infrared spectroscopic chemical identification. Data analysis, result discussion and wrote the main part of the manuscript. 
III Planning and carrying out the direct force measurements and Infrared spectroscopic chemical identification. Data analysis, result discussion and wrote the manuscript with Thomas Ederth.

IV Planning and carrying out the direct force measurements, AFM imaging and Infrared spectroscopic chemical identification. Data analysis, result discussion and wrote the manuscript with Thomas Ederth.

V Planning and carrying out the sensing platform, SEM imaging and fluorescent microscopy. Data analysis, result discussion and wrote the manuscript with Daniel Aili.

Other papers to which I have contributed to during my PhD studies, but which are not part of this thesis:

i Self-assembling Fibers and Nano-Rings from Disulphide-Linked Helix-Loop-Helix Polypeptides

Daniel Aili, Feng-I Tai, Karin Enander, Lars Baltzer, and Bo Liedberg Angewandte Chemie International Edition, 2008, 47, 5554-5556 doi: 10.1002/anie.200801155

ii Polypeptide-guided assembly of conducting polymer nanocomposites

Mahiar Hamedi, Jens Wigenius, Feng-I. Tai, Per Björk and Daniel Aili Nanoscale, 2010, 2, 2058-2061

doi: 10.1039/c0nr00299b 


\section{Contents}

1 Introduction $\quad 1$

2 Antifouling polymer coatings $\quad \mathbf{5}$

2.1 The need for antifouling polymers . . . . . . . . . . 6

2.1.1 Biomedical devices and biosensors . . . . . . . . . . 6

2.1.2 Marine biofouling . . . . . . . . . . . . . 7

2.1 .3 Process industry . . . . . . . . . . . . 7

2.2 Zwitterionic and charge-balanced

ampholytic polymers . . . . . . . . . . . . . . 8

2.3 SIPGP hydrogels . . . . . . . . . . . . . . . . . . . . . . . . . . . . . . . . . . .

2.3.1 Bi-layered gradients . . . . . . . . . . . . . . . . . 11

2.3.2 Patterned gradients . . . . . . . . . . . . . . . . . . . . . . . . . . . . . 14

2.3.3 Copolymer spacer . . . . . . . . . . . . . 16

3 Characterization methods $\quad 21$

3.1 Infrared Reflection-Absorption

Spectroscopy (IRAS) . . . . . . . . . . . . . . . . . . . . . . . . . . 22

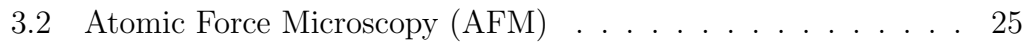

3.2 .1 Atomic force imaging . . . . . . . . . . . . . . 25

3.2 .2 Surface force measurement . . . . . . . . . . . 26

3.3 Ellipsometry . . . . . . . . . . . . . . . . . . . . . . . . . 28

3.4 Imaging Surface Plasmon Resonance (iSPR) . . . . . . . . . . . . . . . . . . 30

3.5 Optical analysis based on Metal Enhanced Fluorescence (MEF) 31

3.6 Scanning Electron Microscopy (SEM) . . . . . . . . . . . . 32

4 Forces and interactions $\quad 35$

4.1 Intermolecular and surface forces . . . . . . . . . . 35 
4.1 .1 Van der Waals force . . . . . . . . . . . . . 35

4.1.2 Electrostatic double-layer forces between surfaces . . . 36

4.1 .3 DLVO theory . . . . . . . . . . . . . . . 41

4.1.4 Hydration and hydrophobic forces . . . . . . . . . . 43

4.1 .5 Steric forces . . . . . . . . . . . . . . . . . . . . . . . . 44

4.2 Adhesion . . . . . . . . . . . . . . . . . . . . . . . . . . . . . . . . . . . . . . . . 45

4.3 Biomolecular interactions . . . . . . . . . . . . . . . 47

4.4 Metal enhanced fluorescence . . . . . . . . . . . . . 47

5 Summary of the results and the included papers 51

$\begin{array}{llr}6 & \text { Future outlook } & 59\end{array}$

$\begin{array}{ll}\text { Acknowledgments } & 61\end{array}$

$\begin{array}{ll}\text { Bibliography } & 63\end{array}$

$\begin{array}{ll}\text { Papers I-V \& Appendix } & 75\end{array}$ 


\section{List of Abbreviations}

$\begin{array}{ll}\text { SIPGP } & \text { Self-Initiated PhotoGrafting and Photopolymerization } \\ \text { IRAS } & \text { Infrared Reflection-Absorption Spectroscopy } \\ \text { AFM } & \text { Atomic Force Microscopy } \\ \text { iSE } & \text { Imaging Spectroscopic Ellipsometry } \\ \text { iSPR } & \text { Imaging Surface Plasmon Resonance } \\ \text { MEF } & \text { Metal Enhanced Fluorescence } \\ \text { SEM } & \text { Scanning Electron microscopy } \\ \text { DLVO } & \text { Derjaguin-Landau-Verwey-Overbeek Theory } \\ \text { AdG } & \text { Alexander de Gennes Model } \\ \text { PEG } & \text { Poly(ethylene glycol) } \\ \text { PCEA } & \text { Poly(2-carboxyethyl acrylate) } \\ \text { PAEMA } & \text { Poly(2-aminoethyl methacrylate }) \\ \text { PMAA } & \text { Poly(methacrylic acid) } \\ \text { PDMAEMA } & \text { Poly(2-dimethylaminoethyl methacrylate) } \\ \text { PHEMA } & \text { Poly(2-hydroxyethyl methacrylate) } \\ \text { PEI } & \text { Poly(ethylene imine) } \\ \text { PSS } & \text { Poly(styrene sulfonate) } \\ \text { AgNPs } & \text { Silver Nanoparticles } \\ \text { Ru(BPY })_{3} & \text { Tris(2,2'-bipyridyl)dichlororuthenium(II) hexahydrate }\end{array}$





\section{Chapter 1}

\section{Introduction}

Coatings are used for protecting objects from environmental damage, or providing aesthetic decorations. Coatings have a long history in human civilization: paint on wood, plating on metals and glaze on ceramics are common examples in our life experience, where rot, rust or cracks are prevented by having the coating layer. The advantage of having coatings is to let this layer take care of the surface events, and the underneath item can still maintain its mechanical strength, structural stability, and so on, without compromising its surface property. This concept is widely used in many applications. In biomedical applications, the surfaces of many devices need to come into contact with biomolecules in the surroundings [1,2], such as proteins, enzymes and metabolites, etc. In vivo studies is a good example: if the task is carried out in a biological environment, the ideal materials must have high biocompatibility. This is where soft matter [3-5] becomes important when the coatings need to function in biological systems. Among soft matter, polymers, whether natural or synthetic, are important and greatly used in biomedical applications, such as in tissue engineering $[6,7]$, implants, and regenerative medicine [8]. Hydrogel is a class of polymers studied and developed extensively for biomedical purposes during the last decade [9-11].

Hydrogel refers to a class of polymers with high water content, often low mechanical strength (low Young's modulus), certain degree of cross-linking, and potentially great biocompatibility. Soft contact lenses [12] are an excellent example. In some applications, fouling and non-specific biomolecule 
attachment to the surfaces, can be problematic. For instance, bacterial films in food and process industries [13,14], inflammatory reactions $[15,16]$ caused by immune response, and biofouling forming ecosystems on marine vessels $[17,18]$. The hydrogels having good resistance to fouling and biomolecular adsorption are of great interests [19-21] for solving the fouling issues for biomedical purposes. As mentioned previously, if a thin layer of coating can be applied onto a substrate or an object that requires anti-fouling property with minimum environmental risk, hydrogels might be a good option. Unlike polymer brushes, which have only one anchor attached to the substrate or surface, hydrogels have cross-link networks in three dimensions. Their swelling in wet state are dependent on the polymer structures, chemical compositions and environment stimulations, and by altering these parameters, the swelling can be controlled.

The work in this thesis is focused on using a gradient-type of thin polyampholytic hydrogel coatings as a model system, for understanding fundamental issues of fouling resistance, which are important for all types of biofouling and non-specific protein adsorption. Similar to zwitterionic materials [22,23], the polyampholytic hydrogels studied here, have both positive and negative charges. These systems have excellent resistance to fouling and attachment of biomolecules at charge balance condition, where the net charge is zero $[24,25]$. When exposed to different chemical environments, for instance, bulk $\mathrm{pH}$ variations, their surface charge and swelling show response to the $\mathrm{pH}$ changes, which indicates that a manipulation of such coatings for surface interaction related functions is possible. Charge-balanced materials are good potential candidate coatings for anti-fouling purposes in biomedical or marine applications. For studying the basic properties and the surface charge controlled fouling resistance, a few combinations of oppositely charged hydrogels were selected as the model system, in which one hydrogel was made as a gradient in thickness grafted onto the other oppositely charged layer of uniform thickness, for varying the charge balance along the gradients in wet state at different $\mathrm{pH}$ values. The interaction between the hydrogel coatings and the approaching objects, in this case, chemically modified colloidal probes, was studied by colloidal atomic force microscopy (AFM) in direct force measure- 
ments. Prior to practical bioassays for general fouling tests, protein adsorption tests on the hydrogel gradients in real-time was a starting point, that would help us to understand how charge-balanced materials interact with biomolecules. Preventing protein adsorption is also important because it can be the first step that the subsequent fouling organisms continue growing from, in marine environment for example. Protein adsorption was followed by using imaging surface plasmon resonance (iSPR), monitoring the real-time interactions on the hydrogel gradients. As mentioned above, their swelling in wet state is dependent on the polymer structure and the compositions. By using imaging spectroscopic ellipsometry (iSE), the swelling profiles of the hydrogels are collected. The model systems characterized using the mentioned methods show a good consistency and correlation between the surface charge, protein adsorption and swelling profiles under various $\mathrm{pH}$ conditions. This is an encouragement for possible manipulations on such charge-balanced materials. In the later work, the hydrogel coatings were also patterned as spots, for imaging their surface topography and roughness by AFM. This gave a good opportunity for comparing the thicknesses obtained from AFM and ellipsometry data. As demonstrated in the last paper, the flexibility of hydrogel combinations is a potential option for optical sensing platforms. The long-term goal is to build up the knowledge about these hydrogels and further use them as anti-fouling or sensing coatings. 
$\overline{-}$ 


\section{Chapter 2}

\section{Antifouling polymer coatings}

Some applications which need antifouling and protein resistant polymer coatings, and the polymer materials themselves are described here. A little background of the most well-known antifouling polymer from a wide application perspective: water soluble and low toxicity poly(ethylene glycol) (PEG), can be an example to begin with. Extensive research and development have been done for biomedical applications [26, 27] and still moving on [28, 29]. Their high protein resistance [30] is due to the strong coordination of water molecules along the chain, and steric repulsion from the long chains [31,32]. Repeating EG units are largely used in polymer brushes or hydrogels $[18,33]$. PEG coatings are excellent materials with antifouling properties that could be found in many types of biomedical studies: drug delivery [34,35], biosensors [36], regenerative medicine [37], cell and tissue engineering [37,38]. PEG containing copolymers and PEG-derived polymers were also studied in our previous works $[18,20,39,40]$. However the oxidative degradation is problematic, since it is not long-term stable, and does not retain its protein resistance [41-43].

Hydrogels [44] are polymers with high water content and certain degree of cross-linking. Their low stiffness, low mechanical strength, hydrophilicity and high protein resistance are important for biocompatible applications [9], such as contact lenses [12]. They are also suitable materials for bioanalytical purposes [45], for instance, biomolecular interactions (mainly with proteins, as in Paper I) and antifouling [19] research. In particular the surface-bound 
hydrogels, mostly grafted to/from substrates [44], can offer the interface advantages regardless the geometry and dimension limits. Therefore, grafting hydrogels as coatings on various substrates can provide required characteristics and maintain the supporting strength of substrates. Among these hydrogels, zwitterionic polymers or polyampholytes $[19,22,24]$, show good antifouling properties due to charge balance and strong hydration of the ionized groups [25]. As a consequence, the lack of early electrostatic attraction between surfaces and proteins will lead to lower adsorption in the end. The SIPGP (self-initiated photografting and photopolymerization) [46] ampholytic hydrogels studied in this thesis will be discussed together with other charge-balanced polymers in the following.

\subsection{The need for antifouling polymers}

\subsubsection{Biomedical devices and biosensors}

Biomedical and bioanalytical purposes are in a great need of antifouling coatings, for reducing the undesirable attachment or interactions of biomoledules. Ideally, if a label-free biosensing platform, such as surface plasmon resonance (SPR) is used, in which a mass-related adsorption is used for the detection, the response of the targeted analytes should be distinctly detected while those non-specific activities, such as adsorption or adhesion of other biomolecules, should be suppressed to be as low as possible. However the surface interactions in biofluids including electrostatic or hydrophobic attraction can lead to a significant adsorption. Commercially used dextran [47], which is a glucosebased polysaccharide coating used as the matrix for immobilizing ligands in biosensors, do face certain challenges in degradation and stability [48, 49]. New antifouling coatings are still in demand, in which the sensitivity and selectivity are also expected to be improved. In previous work in our group by Andreas Lasson [20], PEG containing copolymer hydrogels and surface chemistry aiming at protein resistance were studied for biosensor applications. For biomedical use, the complex of biological activities, for instance, protein adhesion and adsorption, bacterial biofilm formation, immune reactions, and so on, cannot be handled by a universal antifouling coating. The great challenge 
here is the complexity of in-vivo, such as body fluids, aqueous environment with high ion concentration and various types of biomacromolecues involved. A general antifouling solution might not be practically possible. The research for developing more fouling-resistant and biocompatible hydrogels is ongoing $[21,50,51]$.

\subsubsection{Marine biofouling}

Marine biofouling seems to be a quite different subject compared to biomedical or bioanalytical purposes. However, a non-toxic, fouling resistant surface or coating is also pursued in marine biofouling research. Organisms such as algae, barnacles and mussels, begin with attachment to underwater surfaces, and then adhere to continue populating the surfaces. The formation of these ecosystems can lead to damage of the underwater surfaces, and increase fuel consumption. To reduce the environmental impact, biocide releasing type of coatings [52] are not favorable and should be replaced by the solutions which are more environmentally friendly. Silicone and fluoropolymer based foul-release coatings, are made to fail the adhesion of the fouling organisms, when the vessel reaches a certain speed. They are considered environmentally friendly $[53,54]$. Self-polishing coatings are resins loaded with toxins, and the wearing down of the paint is associated with continuous release of toxins $[55,56]$. Highly hydrophilic polymer coatings, are often protein resistant and usually also difficult for the organisms to attach to. Zwitterionic and PEG containing materials are in this class of antifouling coatings, where PEG has been described above, and zwitterionic materials will be described in more detail in section 2.2.

\subsubsection{Process industry}

Sterilization and disinfection treatment $[57,58]$ to the equipment by either high temperature, water pressure or chemical, irradiation methods in food, pharmaceutical and other processing industries, such as water purification, are highly time and cost consuming. Removal of fungi, bacterial biofilms or protein deposits in the pipe systems can also be quite tough. If the surfaces of the equipment and the pipe system can be antifouling, preventing bac- 


\subsection{Zwitterionic and charge-balanced}

ampholytic polymers

terial adhesion and biofilm formation, or even further biocorrosion, it will be a better solution, which reduces the need for cleaning. Low toxicity and environmental impact are required also in process industries, but polymers do not yet have both the required stability and fouling resistance [59].

\subsection{Zwitterionic and charge-balanced ampholytic polymers}

Zwitterionic materials have an important role in antifouling applications for their high fouling resistance [19] and long-term stability [22,24]. The growing interest in zwitterionic materials for antifouling purposes $[60,61]$ has stimulated work both on zwitterionic SAMs [62,63] and polymers [64]. Zwitterionic polymers, of which the most well-known, polybetaines [25], have equal amount of cationic and anionic groups incorporated in the polymer structure, and exhibit ampholytic behaviors. They are also stimuli-responsive [22, 25] due to the ionized groups altering the polymer structure when the repulsion, hydration or intermolecular forces change between the charge units. For instance, their swelling degree can vary reversibly in response to the $\mathrm{pH}$ and ion strength in the bulk atmosphere, and some are temperature responsive. Strong hydration of the large number of ionized groups in zwitterionic polymers is thought to be the origin of fouling resistance [31, 41,65]: lack of electrostatic attraction, and unfavorable removal of hydration layer. Such a concept should also be applicable to any charge-balanced system, that behaves similarly to zwitterionic materials. A charge-balanced (charge-neutral) SAM surface can be prepared from zwitterionic molecules [66], ensuring that the right ratio of ionizable residues needed to generate net charge neutralization is in place. Similarly, a pseudozwitterionic, or any polyampholytic coating having both positive and negative charge units, could potentially form a charge-balanced system, with possible fouling resistance provided by ion hydration.

Hydrogels are highly swollen in aqueous environment, and the steric repulsion arising from entropy is also a significant contribution to the non-fouling property. By the inspiration from zwitterionic materials, the polyampholytic 
gradients were created to mimic the charge balance effect but employed the benefits of the SIPGP process: quick formation of copolymers and flexible monomer choices. The reason for choosing carboxylic acid and primary and secondary amine groups, instead of paired sulfonate/ammonium (quaternary amine) was that, the weak acidic/basic groups have variable degrees of ionization when the bulk $\mathrm{pH}$ is changed. Consequently the charge balance can be tuned by the $\mathrm{pH}$ value, offering a chance to study the interactions with approaching objects, in our work, charged probes and proteins, in response to changes in the surface charge, and in particular, such changes appearing as a result of variations in $\mathrm{pH}$ or salinity.

\section{$2.3 \quad$ SIPGP hydrogels}

The hydrogels used and characterized in this thesis were grafted onto different substrates (gold, silicon, or glass) by Self-Initiated PhotoGrafting and Photopolymerization, SIPGP, described in Paper I, which is one of the UV-initiated free-radical polymerization reactions. The advantages of such reactions are: applicable to a wide range of monomers, rapid reaction process, flexibility in the choice of substrate (anything organic), and no need to use initiators or catalysts. The possible degradation of the film under prolonged polymerization could be an issue. The polymerization occurs in free monomer solutions, resulting in high variation of polymer chains that gives less well-defined polymer structure. In the SIPGP method, the process is carried out without initiator: monomers were dispersed in water-based buffers, and upon the UV-C photo stimulation, the monomers are photoexcited to abstract hydrogen where a new site for grafting initiation is formed. The set-up of SIPGP and the reaction is illustrated in Figure 2.1. Prior to the grafting, the substrates need to be coated by organic films, by silanization or other SAMs, or spin-coated polymers (polystyrene, Zeonor ${ }^{\circledR}$ and similar). The bare metal, oxides, or glass substrates cannot be grafted without organic coatings, though the type and functional groups of the organic coatings are not important.

An SIPGP reaction Scheme has been described by Deng et al. [67] using styrene as the example. A more detailed discussion and work were reported 


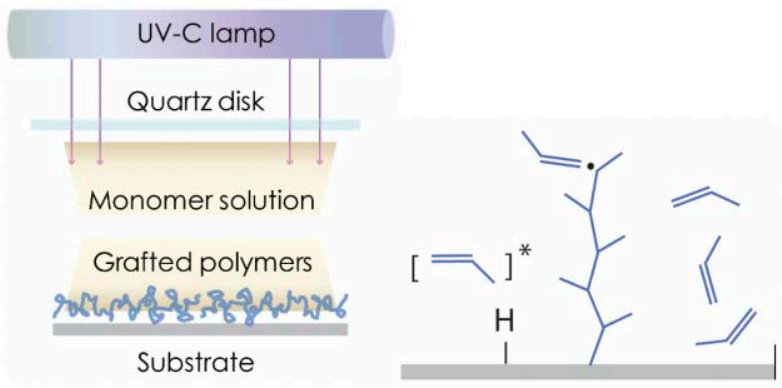

Figure 2.1: Illustration of the SIPGP set-up. The UV-C lamp irradiates through a quartz disk which the substrate sticks onto by water meniscus of the monomer solutions. The right sketch shows the photoexcited monomer abstracting the hydrogen at the surface, and a propagating radical on the growing polymer chain.

previously by Tobias Ekblad [46].

(1)(A monomer) $M \stackrel{U V}{\longrightarrow}[M]^{S}$ (UV excited to a singlet state)

(2)(Monomer at the singlet state) $[M]^{S} \rightarrow[M]^{T}$ (Stable triplet state)

(3) $[M]^{T} \rightleftharpoons[M]^{:}$(Two radicals formed)

(4) $[M]^{:}+($Attacked monomer $) M \rightarrow \dot{M}-\dot{M}$

(5) $\dot{M}-\dot{M}+$ (More attacked monomers) $n M \rightarrow[M]_{n}$ (Homopolymer in solution)

(6) $M{ }^{*}+S u-H$ (Hydrogen abstracted at the surface) $\rightarrow \dot{M}-H+S u$ (Surface-bound radical)

(7) $S u+n M \rightarrow S u[M]_{n}^{\circ}$ (Grafted polymer)

(8) $M^{*}+S u[M]_{n}-H \rightarrow \dot{M}-H+S u[M]_{n}^{*}$ (Polymer-bound radical)

(9) $S u[M]_{n}^{\circ}+m M \rightarrow S u[M]_{n}[M]_{m}$ (Branching)

(10) $[M]_{n}+S u$ or $S u[M]_{n} \rightarrow S u[M]_{n}$ or $S u[M]_{n}[M]_{m}$ (Grafted polymer, branching)

The SIPGP reaction is shown with steps above. UV excited monomers (1) activate the free radical formation (2-4) and then initiate homopolymerization in the solution (5) or abstraction of hydrogen at the surface (6), which results in surface-bound radicals that drives polymerization of grafted chains (Shown as the right sketch in Figure 2.1) (7). If hydrogen abstraction occurs 
in grafted chains (8), this will then lead to branching in the polymer network (9). Similar branching, cross-linking and grafting could also occur until the termination of polymerization process (10).

As mentioned above, the monomer options are flexible in SIPGP, and the protocols applied on various substrates can be different to optimize the results. Some of the parameters which are most important in the SIPGP process, are monomer concentration, buffer $\mathrm{pH}$, and UV-exposure time. From experiences, the monomer concentration was sufficient in the range of $1-10 \%$ $(\mathrm{v} / \mathrm{v}$ or $\mathrm{w} / \mathrm{v}) ; \mathrm{pH}$ range of buffers between $4.5-6$ depending on monomers; long UV-exposure may result in polymer degradation, therefore for optimum film thickness one only needs $3-6$ min UV irradiation. The average thicknesses of hydrogel films formed by SIPGP is in the range of $5-100 \mathrm{~nm}$. Though the UV-exposure is the energy source which drives the reaction, further irradiation did not result in thickness increase but mostly degradation of the polymers, and higher concentration of monomers did not give good quality of films either. The detailed discussion regarding the mechanism and comparison of SIPGP to other type of grafting methods were described elsewhere $[46,67,68]$. As discussed and concluded in Paper III, their physical properties in terms of the molecular weight, polymer structure and grafting density remain undetermined due to the fact that the polymer structure of SIPGP hydrogels is less well-defined and difficult to determine.

\subsubsection{Bi-layered gradients}

In Paper I to IV, the model systems are bi-layered hydrogel films with two oppositely charged polyelectrolytes, and which we refer to as polyampholytic gradients. As reported in Paper I and II, the hydrogel gradients with positive and negative charge units form regions which behave similarly to zwitterionic copolymers in the charge-balanced region, having a low net charge when interacting with proteins, and therefore minimize the protein adsorption. The gradients were composed of one polyelectrolyte with thickness gradient, grafted on an uniform bottom layer, which had the opposite charge. Figure 2.2 shows the how the hydrogel gradients were made. This gave a continuously varying distribution of one charge type, allowing us to 


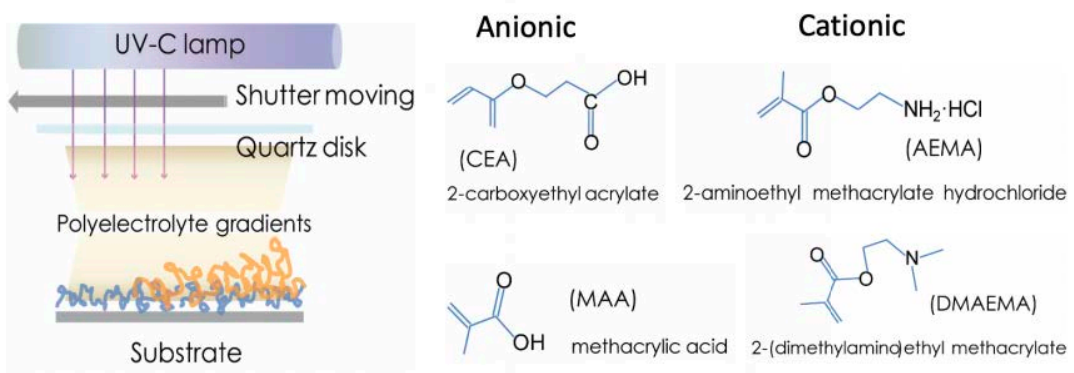

Figure 2.2: A gradient type of polyelectrolyte film is grafted by varying the UV-exposure time with a motorized moving shutter, which results in a thickness gradient along the moving axis. In Paper I to III, the gradients were formed on top of a uniform bottom layer, as shown in this sketch. The monomers used are shown to the right.

find the charge-balanced region along the gradient. The chemical information was then correlated to the real positions on the gradients, by reassembling IR spectra obtained along the gradient in a three-dimensional fashion. The biomolecules, in this case proteins, were found to to interact with the hydrogels mainly through electrostatic interactions. The gradients with lateral charge distribution were found to result in a selective protein adsorption, as reported in Paper I and II, corresponding to the expected electrostatic attraction or repulsion, as estimated from the net charge of the proteins. In other words, the protein adsorption profile can indicate the surface charges along the gradients: the negatively charged proteins should preferably stick on the positively charged side of the hydrogel gradient. The detailed results of protein adsorption monitored by iSPR and surface charge/force characterization by direct force measurements with colloidal AFM were included in Paper I and II.

The theory and experimental models of polymer brushes have been developed over a long history [69-74]. A polymer brush is a well-defined structure that has end-anchors bound to the substrates but no cross-links between polymer chains, which results from a careful control during polymerization, as obtained with methods like the ATRP [75] (atom transfer radical polymeriza- 
tion) process. In this type of brushes, the grafting density and thickness can be in good correlation to the swollen properties [19]. The swelling behavior of neutral, and subsequently charged, brushes is used as a starting model in an effort to model the interaction of collodial probes with swollen regions of the hydrogel gradients. As described and discussed in Paper III, the force interactions on the gradients, far from the charge-neutral region (which is highly compressed), were fitted with an Alexander de Gennes (AdG) model [76,77] modified by Dunlop [78] et al.. The fitting result indicates a dense structure and similarity to strong polyelectrolyte brushes in electrostatic and steric behaviours. The steric repulsion was found to dominate the force interaction away from the charge-balanced region, and beyond the screened electrostatic double-layer force, but we were unable to separate the contribution of either. This led to a study of mixed SAMs (self-assembled monolayers) with a series of mixing ratios, in which both acidic and basic groups are populated on the surface, and not distributed in a swollen volume. Such a pseudo-zwitterionic system was expected to provide us further knowledge of net surface charge dependence to $\mathrm{pH}$ changes and chemical compositions. However the net surface charge does not represent quantitative chemical composition of the mixed SAMs, and the fact that in the hydrogels, the force interactions were dominated by the steric force, were the main reasons that this study was not successful and did not give significant input on resolving the force interactions in the hydrogels. The details of the mixed SAMs study are described in Appendix.

The swelling of cationic PAEMA and PDMAEMA were found to be smaller than that of anionic PCEA and PMAA in the $\mathrm{pH}$ range between 4.5 to 7 , even at the thick end of the gradient. This might be due to the ionization of the charge units being different, and the charge neutralization between the two hydrogels.

In summary, the bi-layered polyampholytic hydrogel gradients fabricated by SIPGP have rather complex polymer structure with both branching and cross-linking $[20,79]$ that is difficult to be resolved. They were shown to have ampholytic surface charge that can be tuned by pH in Paper II, with a clear selective protein adsorption profile. And the adsorption minimum, where the charge was balanced, moved in response to the change of $\mathrm{pH}$. 
The force interactions collected by the colloidal AFM probe, also showed the charge-balanced region relocation on the gradient. The correlation between force interactions with protein adsorption was demonstrated in this model system, which shows the potential manipulation possibility of external stimuli. Previous studies [20,79], suggested that these hydrogels are both branched and cross-linked. High order of branches results in dense polymer conformation, however the degree of cross-linking and grafting density are difficult to determine. The degree of interpenetration between the two layers also remains to be investigated.

Though it seems that the grafted hydrogels made by SIPGP have some disadvantages that these parameters, such as grafting density and molecular weight, are not available, the advantages they have are quite important from a manufacturing perspective. The hydrogel coatings can be grafted on various substrates with a rapid and simple single step, which only requires little pre-modification of the substrates. Patterns can be made with photomasks during the UV-curing, shown in Paper IV. The set-up is simple and with low cost, which can be considered for large-scale output [80,81]. Since the monomer options are very wide, the coatings can be made to custom functions according to the use, for example in Paper I and II, for protein selective adsorption and as a stabilizing spacer in Paper V.

\subsubsection{Patterned gradients}

In previous work by Ekblad and Larsson [18,20,46], SIPGP hydrogels were patterned on various substrates, with the intent to prepare materials suitable for microarray applications. Figure 2.3 shows a gradient of PDMAEMA is patterned as spots, with a diameter of $100 \mu \mathrm{m}$ and $50 \mu \mathrm{m}$ interval on a uniform layer of PMAA, from Paper IV. The major advantage of the patterned spots here is that the uniformed bottom layer of PMAA and the spots of PDMAEMA can be studied independently. The contrast in the AFM images, both in height and phase, provide further information that was not available from ordinary gradients, such as surface roughness and the adhesion (stiffness of polymer). These surface properties could be polymer dependent, and also varying along the gradient as the polymer composition changes. The force 


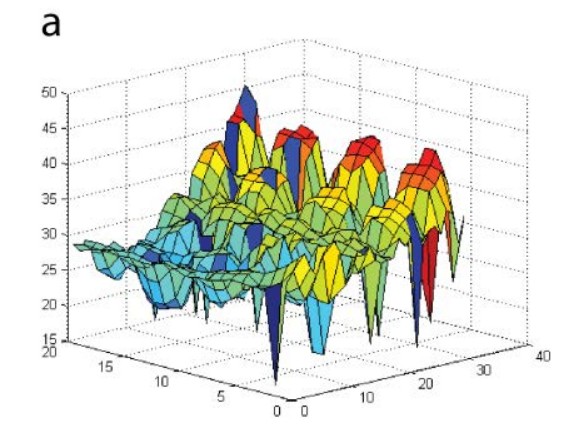

b


Figure 2.3: A spot gradient from Paper IV, made of PDMAEMA on uniform PMAA. A gradient can provide both thickness and charge distribution along the gradient: (a) is the wet thickness in $1 \mathrm{mM} \mathrm{PB}$ buffer at $\mathrm{pH} 6$ obtained from iSE data, (b) is a cartoon of the spot gradient (not to scale) (c) is the force from 5 spots probed by a negatively charged MUA probe in $1 \mathrm{mM} \mathrm{PB}$ buffer at $\mathrm{pH} 6$ 
curves shown in Figure $2.3 \mathrm{c}$ were obtained with a negatively charged, MUA coated colloidal probe in $1 \mathrm{mM} \mathrm{PB}$ buffer at $\mathrm{pH}$ 6. The electrostatic interaction clearly switches from repulsion (at Spot 45), through neutral (at Spot 43) to attraction (from Spot 41 and onwards), indicating that the attraction between the MUA probe and the positively charged PDMAEMA increases via the thickness of the gradient. The swelling of the spots in $\mathrm{PB}$ buffer at $\mathrm{pH}$ 6 (in Figure 2.3 a), showed large errors, which could be expected while the hydrogel film was swollen and became inhomogeneously dilute. The polymer structure of hydrogels made by SIPGP is difficult to determine, which limits our knowledge of this system (earlier neutron scattering results showed high water content and thickness about twice swollen [79]). The bi-layered gradients are in particular complex due to the interpenetration grafting. In Figure $2.3 \mathrm{~b}$, the cartoon does not specify the structure of the interface between the PMAA and PDMAEMA. From the SIPGP process, the bottom layer should swell in the solution of the second monomer, when it is ready to be irradiated with the UV light. The cationic monomers are expected to be attracted by the electrostatic force, and penetrate into the swollen anionic polymer network. This forms a certain degree of preorganization of the cationic monomers, and results in an interpenetrating grafting [82].

The thicknesses of the spots in air, were modeled from the iSE data, and the thicknesses are consistent with those in Paper III and the results measured by AFM. While in the wet state, the two methods for estimating the film thicknesses differ significantly in their results, due to the very different input data used in the two cases. In Paper IV, the changes of refractive index in a swollen film (parameter for iSE), and the interaction between the AFM tip and hydrogels (parameter for the height image), are discussed in detail, to give a background when interpreting and comparing the thicknesses obtained from these two methods.

\subsubsection{Copolymer spacer}

In Paper V, the copolymers of AEMA and HEMA (2-hydroxyethyl methacrylate) were used as a stabilizing spacer to adsorb the citrate protected silver NPs for metal enhanced fluorescence. PAEMA is positively charged there- 
fore it was selected to attract the negatively charged Silver NPs. P(AEMAco-HEMA) were grafted on an organic bi-layer of polyelectrolyte PEI/PSS (polyethyleneimine/polystyrene sulfonate) adsorbed on glass substrates. The thickness of P(AEMA-co-HEMA) was varied by the UV-exposure time, in the range between $5-25 \mathrm{~nm}$. HEMA is a well-known monomer, commonly used for preparing cross-linked hydrogels, which have a water content of $40-50 \%$ and also good protein resistance. The purpose of copolymerizing HEMA with AEMA, is to speed up the polymerization process and increase the total film thickness. From practical experiences, the film thickness of PAEMA or PDMAEMA itself can hardly reach a higher thickness than $15 \mathrm{~nm}$. Using HEMA mixed with AEMA in monomer solutions, avoids the long UV-exposure which causes bleaching of the fluorophores, and gives a better stability of the films.

Figure 2.4 shows the chemical structures of the polyelectrolytes, PSS and PEI, used for immobilizing the flourophores, and as the organic layer for SIPGP process. Figure 2.5 shows the configuration of the MEF platform with $\mathrm{P}$ (AEMA-co-HEMA) used in Paper V. Previous work, where P(HEMA-coPEGMA), (PEGMA, Poly(ethylene glycol) methacrylate) films were also fabricated by SIPGP and studied for biomedical and antifouling purposes [18], showed that the structure was dense and cross-linked [46].

As illustrated in Figure 2.5, the purpose of the configuration of the MEF platform in Paper V, was to have a well-defined distance between the fluorophores and the AgNPs, which is an important parameter to have a control of to achieve high enhancement. If the NPs were immobilized on the substrate instead, the hydrogel film used to cover the AgNPs has to be thicker than $40 \mathrm{~nm}$ (the diameter of the NPs), and may still suffer from the distortion of morphology. Therefore the fluorophores were embedded in the PSS layer, which is adsorbed on PEI to form the organic bi-layer. The drawback with such a configuration is that the fluorophores will be UV-irradiated together with the monomer solutions during the SIPGP process, and this irradiation will degrade the fluorophores.

The optimum monomer ratio, UV-exposure time and the surface density of PAEMA for catching NPs by electrostatic attraction, were discussed in Paper V. In principle, the optimum distance for MEF is dependent on the 

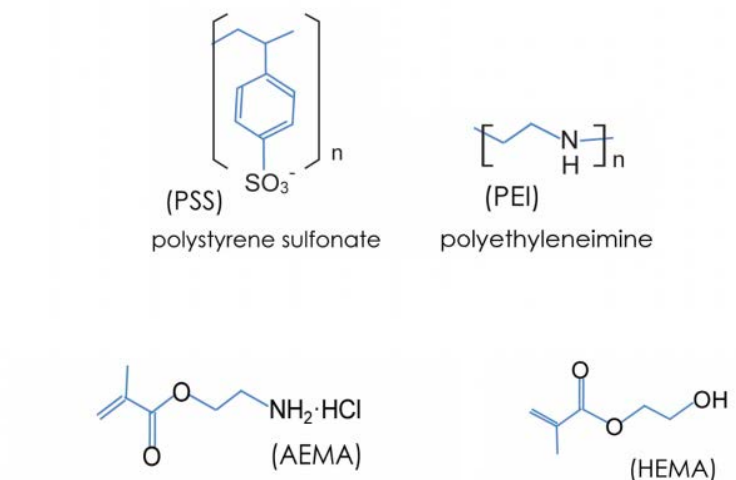

2-aminoethyl methacrylate hydrochloride

2-hydroxyethyl methacrylate

Figure 2.4: Chemical structures of PSS, PEI, AEMA and HEMA. PEI and PSS adsorbed as a bi-layer on glass substrates, to be the organic film for (AEMA-co-HEMA) to graft from.

hydrogel spacer thickness, so if the gradient type of spacer is applied, the MEF effect should be seen on certain positions of the gradient. However, since AEMA content increases with longer UV dose and film thickness, the particle density has to be quantified separately. The detailed results and discussion were included in Paper $\mathbf{V}$. The combination of hydrogel spacer and the nanoparticles is flexible in this configuration. The first step is to immobilize the fluorophores. For instance, if the fluorophores have handles which can covalently bind to the organic layer or the substrates, the density and distribution of the fluorophores can be quantitatively controlled. The organic layer is required for SIPGP but the options are rather wide, SAMs or spin-coated polymers can act as good as adsorbed polyelectrolyte. The spacer choice is often determined by how later on the NPs are going to be attached to the spacer. In our case, the NPs were caught by electrostatic attraction, thus the hydrogel spacer needed to have opposite charges to that of the NPs protective capping. The final step is then to optimize the possible parameters, such as NPs density and the thickness of the spacer. To measure the MEF effect in this configuration is simple. Basic fluorescence microscopy together with a spectrometer is sufficient. If the spectrum of each pixel of 


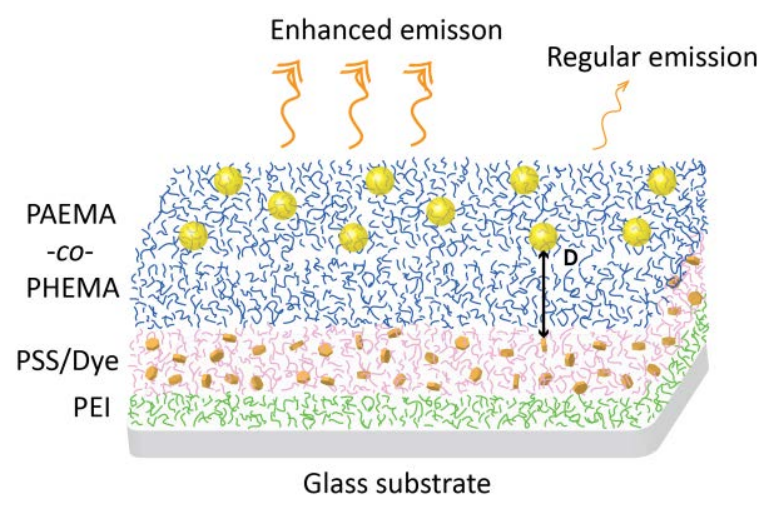

Figure 2.5: P(AEMA-co-HEMA) hydrogel film was used as the stabilizing spacer for MEF (metal enhanced fluorescence). The fluorophores were blended with PSS which adsorbed as a bi-layer with PEI onto a glass substrate. The spacer was expected to tune the distance for reaching optimum that results in high enhancement. D is the film thickness and the average distance between the NPs and fluorophores.

the image can be recorded, the enhancement factor can the be evaluated at different positions and possibly correlate to the particle coverage on the surface. If there are significant emission variation on certain pixels, the intensity can indicate the aggregation of AgNPs. The aggregation of NPs could either give larger enhancement, or quenching, depending on their aggregation scale, and how the fluorophores are placed around these aggregated NPs. There are also other interests related to MEF, such as life-time or transient state measurement, near field optical analysis, and single molecular probe, that might benefit from the enhancement, and this platform is demonstrated as a preliminary simple model. 
2.3. SIPGP hydrogels 


\section{Chapter 3}

\section{Characterization methods}

The SIPGP hydrogel coatings were characterized by surface sensitive methods, for improving our fundamental knowledge about their surface properties and interactions. For the surface chemical analysis, microscopic infrared reflection absorption spectroscopy (IRAS) was used to collect Infrared spectra. The spectra were assembled as chemical maps that shows the surface distribution of the materials. In Paper I to IV, direct force measurements by colloidal-probe AFM were used to determine the surface forces on the hydrogel gradients. Null ellipsometry was used to estimate the thicknesses of the hydrogel films, and by using its spectroscopic/imaging mode (iSE) with a fluidic cell setup, the optical output was used to follow the swelling of hydrogels in the wet state. In Paper I and II, for observing the surface interactions with proteins in real-time, imaging Surface Plasmon Resonance (iSPR) was used to track the protein adsorption on the gradients at different $\mathrm{pH}$. The correlation between surface forces, swelling and protein adsorption profiles, provided valuable information for understanding their fouling resistance. In Paper IV, the gradients were patterned as arrayed spots, and their surface topography, roughness and thicknesses were imaged by atomic force microscopy (AFM) both in air and buffers. These images also offer us an opportunity to compare the thicknesses obtained by modelling the ellipsometry data. In Paper V, hydrogel films with ionizable residues were made for catching oppositely charged silver nanoparticles (AgNPs) on this hydrogel-based MEF platform. Fluorescence microscopy was used when eval- 


\subsection{Infrared Reflection-Absorption}

Spectroscopy (IRAS)

uating the enhancement resulting from variation of different parameters. A hyperspectral fluorescence imaging system collected the spectra from all the pixels simultaneously, which were then used to calculate the enhancement. The varying intensities on different pixels can help to allocate AgNPs aggregation. The spatial distribution of AgNps on the hydrogel films was imaged by scanning electron microscopy (SEM). The following sections will describe how the characterization tools were used, and the important information they provided. Their limitation and other relevant issues are discussed as well.

\subsection{Infrared Reflection-Absorption Spectroscopy (IRAS)}

IR spectroscopy is a type of vibrational spectroscopy, which has a long history of being broadly used for identifying and analysing chemicals [83]. Absorption bands in the spectra represent specific vibrational transitions upon infrared light absorption, which can be seen as chemical fingerprints. This means that each chemical component has its unique spectrum, and one can use IR spectra to identify unknown materials. IRAS is a common configuration used to obtain absorption spectra from very thin layers of materials deposited on reflective substrates [84]. FT-IR microscopy in grazing-incidence reflection mode (IRAS by IR microscope) was used when characterizing the surface chemical distribution along the hydrogel gradients in Paper I to III, which makes a two-dimensional data presentation possible. Details of this will be explained after the IRAS principle is described. Confirming the chemical composition of hydrogel films is essential in all the work included in this thesis, and the IR spectra also contain information about functional groups, hydrogen bonding and structural conformation [85], which could help us to learn how they interact with the environment. From a integration of specific peaks, we could obtain the relative thicknesses of the gradients. From the peak positions and intensities, we could see the chemical composition variation along the gradient. For example, the carbonyl peak intensity of the hydrogel gradients was used to follow the film thickness in Paper I to III (because we knew that the intensity is proportional to the amount of 
Chapter 3. Characterization methods

material). The integral of the carboxylic acid peak of the mixed SAMs was used to follow the mixing ratio of molecules adsorbed in a monolayer (details in the Appendix). Though infrared spectroscopy in general gives a semi-quantitative analysis, it is still a very useful tool that brings informative results in terms of relative amounts, and chemical component analysis.

\section{IRAS principle}

In a molecule, the vibrations between the atoms may result in oscillating dipole moments. According to the gross selection rule [83], vibrational transitions occur when the dipole moment changes are non-zero in the vibration mode, and the frequency of the dipole moment oscillation is in resonance with the electrical field oscillation of the incident IR light at absorption. These vibrational frequencies are active modes and are those modes that can can be seen in the IR spectra. A molecule has $3 N-6$ vibration modes $(3 N-5$ for a linear molecule, and $N$ is the number of the atoms in the molecule), which results in multiple absorption bands in its spectrum. In an IRAS spectrum, the absorbance is presented against the conventional unit of wavenumbers $\left(\mathrm{cm}^{-1}\right)$. When using an IRAS setup, the surface selection rule needs to be considered due to the nature of light propagation on a reflective surface: the reflected light is phase shifted. The incident light is considered as a plane electromagnetic wave $E$, dived into two components: parallel ( $p$-component) and perpendicular to ( $s$-component) the plane of incidence.

Figure 3.1 shows the light components of a wave reflected from a surface. The reflected s-component has a destructive phase shift upon reflection, that cancels the incident s-component for all incidence angles. The phase shift of the reflected p-component is depending on the angle $\theta$ of incidence. As a result of the cancellation, only those vibrational modes having transition dipole moments parallel to the p-component on the surface can be seen. This is described as the surface selection rule shown in Equation 3.1:

$$
I \propto|\vec{E} \cdot \vec{M}|^{2}=|\vec{E}|^{2} \cdot|\vec{M}|^{2} \cos ^{2} \theta
$$

Where $M$ is the transition dipole moment, $E$ is the electrical field. The intensity $I$ of a vibrational mode depends on the angle between $E$ and $M$. 


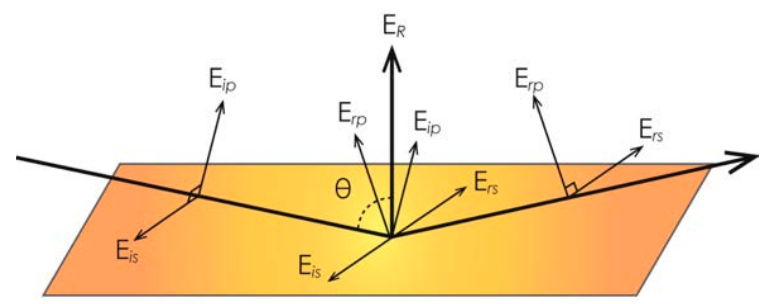

Figure 3.1: Light components of a wave reflected from a metal surface. The incident (i) wave is divided into two components: parallel $\mathrm{E}_{i p}$ and perpendicular $\mathrm{E}_{i s}$ to the plane of incidence, when $\theta$ is the angle of the incidence. The reflection ( $\mathrm{r}$ ) of $\mathrm{E}_{r s}$ with s-component is phase shifted about $180^{\circ}$ at all angles of incidence, which leads to cancellation of the incident and reflected s-component. $\mathrm{E}_{r p}$ and $\mathrm{E}_{i p}$ contribute to the resulting electric field $\mathrm{E}_{R}$ near the surface

\section{IRAS by FT-IR microscopy}

The wavelength of the light in the mid-IR region is in the range $2-20 \mu \mathrm{m}$, and with a microscopic configuration, a lateral resolution near the IR light diffraction limit, about $10 \mu \mathrm{m}$, can be expected. The reflection-absorption data acquired by an IR microscope is obtained with a different setup compared to ordinary FTIR spectrometers. A grazing angle IR objective was used to collect the reflection signal from the hydrogel gradients. The full range (400 to $4000 \mathrm{~cm}^{-1}$ ) spectra along the gradients were collected by the IR objective at fixed distance intervals on the surface, and eventually plotted in a stacking fashion (see in Paper I to III): Absorbance on the vertical axis, plotted against spectral range and position along the surface. At such a circumstance we were able to follow the spectral changes along the hydrogel gradients, and to compare the spectra at different positions. For thicker samples, one can also use an FPA (Focal-Plane Array) detector to collect the spectrum in each pixel at a two dimensional (XY) surface. This type of chemical map will show how the presence or intensities of specific bands (vibrational modes) are distributed over the surface. 
Chapter 3. Characterization methods

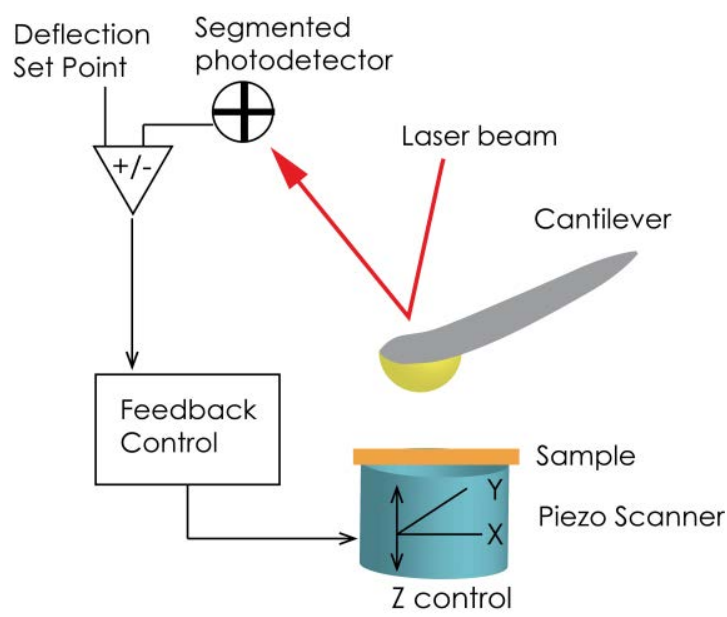

Figure 3.2: A sketch of the beam-bounce AFM principle. The cantilever deflection is recorded by the photodetector, while the feedback controller is regulating the piezo scanner in $\mathrm{Z}$ axis (following the sample height profile) to keep the deflection constant, and near the setpoint (giving a constant force) simultaneously.

\subsection{Atomic Force Microscopy (AFM)}

Atomic force microscopy is a commonly used type of SPM [86] (scanning probe microscope), which operates on intermolecular forces between the tip and the sample surface at very close separation (typically $0-10 \mathrm{~nm}$ ). A beambounce AFM configuration is used in our work and shown in Figure 3.2.

In this thesis work, imaging mode was used for scanning the topographical features of the hydrogel spot surfaces, which also gives surface roughness and cross-section profiles in Paper VI. Force detection mode was used to measure the surface forces on the hydrogel films (Paper I to IV).

\subsubsection{Atomic force imaging}

AFM is a non-destructive imaging tool under certain conditions, which gives high resolution at nanometer level in lateral, and below nanometer in vertical direction. In our setup, the imaging contrast ultimately relies on the 
Pauli repulsion, and together with the geometry of the tip $\left(\mathrm{Si}_{3} \mathrm{~N}_{4}\right.$ ultra sharp tips, with low spring constants), the lateral resolution in our setup is a few nanometer. Since it also allows operation in liquid, the hydrogel spots studied in Paper IV were characterized in both dry and wet states, which was a great advantage because the swelling and protein adsorption were also monitored in wet condition. We were then able to measure the surface topography, roughness, and thickness changes upon swelling from the dry to the wet state. Though practically there are some challenges when working in liquid: a) the stability of the spring is worse in acidic environment (we were not able to scan the surface below pH 5) which leads to a high noise level. b) the hydrogels swell in the solution and might attach to the surface of the probes, which might result in adhesion of the tip on the hydrogel surface. c) the $\mathrm{pH}$ range (above 6 ) where we were able to do imaging is not enough to cover the whole $\mathrm{pH}$ range (between 4.5 to 7 ) we need for observing the surface charge changes observed with other methods. Thus, unfortunately the information we could collect by imaging is incomplete, due to the nature of the tips.

\subsubsection{Surface force measurement}

Direct force measurements performed in this thesis were done by colloidal probe AFM. A colloidal particle attached to the cantilever for use in force measurement is often modified according to the needs of the interactions to be measured. The particle is usually between a few to a few tens of micrometers, to give a larger total force on the particle surface, to ease the detection of small forces. A large particle can also give a well-defined radius, which allows the forces to be converted to the interaction free energy $F / 2 \pi R$ via the Derjaguin approximation [87].

For instance, MUA (11-Mercaptoundecanoic acid) SAMs modified probes were used to probe the surface charges on hydrogel films in Paper I to IV, and help us to analyze the surface forces and interactions. Figure 3.3 shows the electron micrograph of a gold coated silica particle attached to a triangular cantilever. When the probe is brought into contact with the sample surface, the deflection of the cantilever is recorded by the photodetector as a function of position of the $\mathrm{Z}$ scanner. A raw force - distance curve 
Chapter 3. Characterization methods

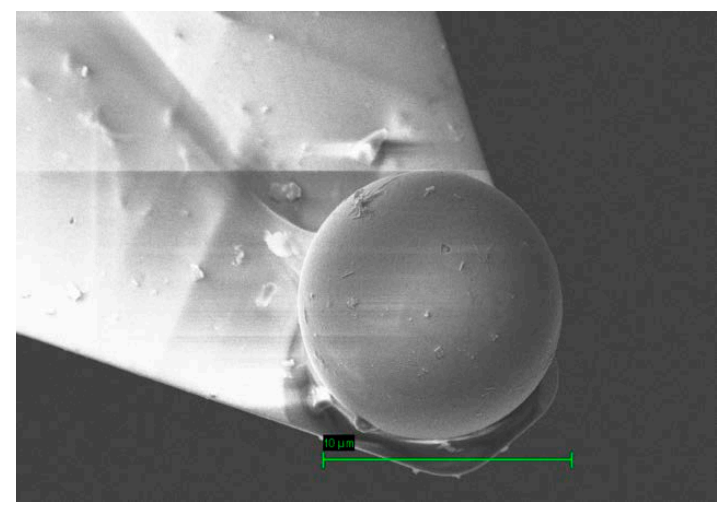

Figure 3.3: SEM image of a colloidal probe used in our work. A gold coated silica particle is attached to a triangular cantilever with a low spring constant, typically about $0.1 \mathrm{~N} / \mathrm{m}$. The scale bar is $10 \mu \mathrm{m}$, indicating the diameter of the particle. The particle is then chemically modified by SAMs with different end groups.

is collected from the approach to a complete withdrawal of the probe, the ramped $\mathrm{Z}$ axis displacement of the $\mathrm{Z}$ scanner and the cantilever deflection are recorded. This tip - sample force follows the Hooke's law: $F=-k x$, where $x$ is the displacement, and $k$ is the spring constant. In this relation, the force is normalized by the particle radius while the cantilever is treated as a linear spring. The displacement of $\mathrm{Z}$ scanner is converted to the separation between the probe and the surface. Assuming a hard-wall contact, where the separation between the probe and surface is assumed to be zero (see Figure 3.4), in the constant compliance region [87], we can see that the force curve has a constant slope. The output signal is converted to force/radius $(\mathrm{F} / \mathrm{R}, \mathrm{mN} / \mathrm{m})$ against the separation (nm) curves.

A force curve can contain information about different types of surface interactions [89], for instance in our hydrogel films, we observed electrostatic attraction between the probe and the hydrogels. At the charge-balanced region, a small jump-into-contact indicates the van de Waals forces. The long range steric repulsion is also observed at the thick end of the gradients. Force measurements are not limited to colloidal interactions or surface forces as shown here, it is also applicable to other types of interactions, for instance, 


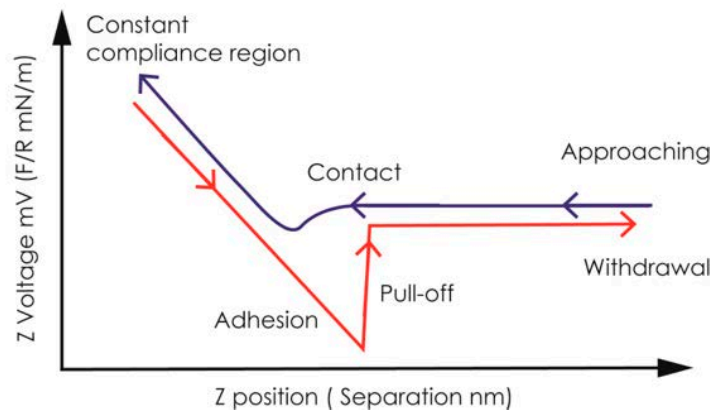

Figure 3.4: A typical force plot cycle [88]. The blue curve represents the approach and the red curve is the withdrawal. The deflection of the cantilever is recorded during the whole force cycle. In practice, the units are converted into Force/Radius $(\mathrm{mN} / \mathrm{m})$ versus Separation (nm).

the antibody-antigen rupture [90] force estimation.

\subsection{Ellipsometry}

Optical characterization methods often have two major advantages for measuring soft matter like the hydrogels in our work. One is that they are usually non-destructive, rarely damage or modify the samples during the measurement. The other is that they can have high sensitivity and/or resolution. Ellipsometry is one of the common methods that we used for characterizing hydrogels. Dry film thicknesses of films with homogeneous thickness were measured by a single-wavelength null ellipsometer. Gradients (wet and dry) were measured with a spectroscopic imaging null ellipsometer (iSE).

\section{Principle of Null-Ellipsometry}

Light has electromagnetic components that are parallel and perpendicular to the incidence plane, upon reflection at a surface. An ellipsometer sends the incident light to the sample surface and then measures the polarization change from the reflected light. At the null condition [91], as shown in Fig- 
Chapter 3. Characterization methods

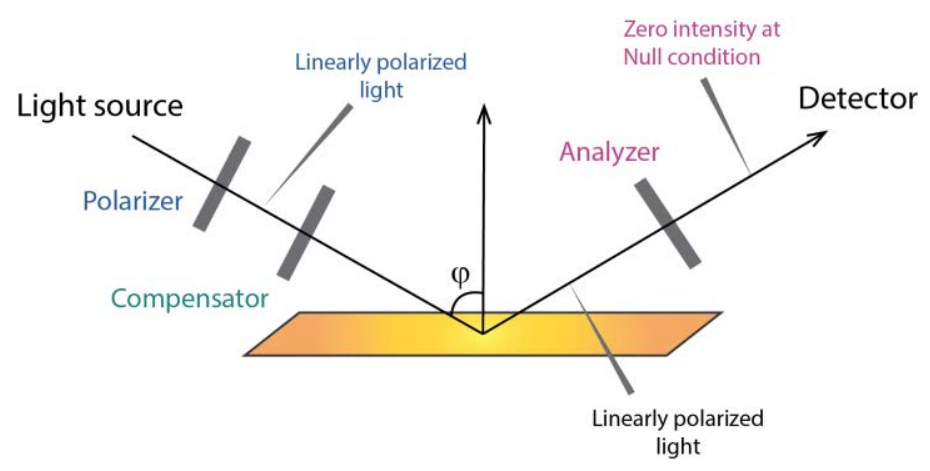

Figure 3.5: A schematic view of a a PCSA (polarizer-compensator-sampleanalyzer) at the null condition. $\varphi$ is the angle of incidence. Adapted from [91].

ure 3.5, the polarizer and the compensator are searching polarizations which will become linear after reflected by the sample surfaces, and extinguished by the analyzer. Since this method detects the polarization difference between the incident and reflected light, with the parameters of amplitude $\Psi$ and phase shift $\Delta$, the sensitivity is extremely high, which can give resolution down to $\AA$ level in modelled thickness.

For dry films having constant thicknesses, with the refractive indices, the film thicknesses were then modelled by Fresnel equations using the threelayer model [91]: ambient/organic film/gold film, while the organic film is assumed to be isotropic, transparent and have a refractive index of 1.5 [92]. iSE was used in Paper I to IV, had a CCD camera to obtain the lateral resolution. The hydrogel gradients were measured over a range of wavelengths (spectroscopically) to verify the swelling in buffers, and refractive indices obtained from single-composition (homopolymer) layers were used for the thickness modelling.

A Bruggeman effective medium approximation [91] was used for modelling the dilution of the polymer with water or buffer during swelling. In these models, the hydrogels were assumed to form a single, uniform layer, in which the water content was allowed to vary. Details are described in Olof Sterner's 
3.4. Imaging Surface Plasmon Resonance (iSPR)

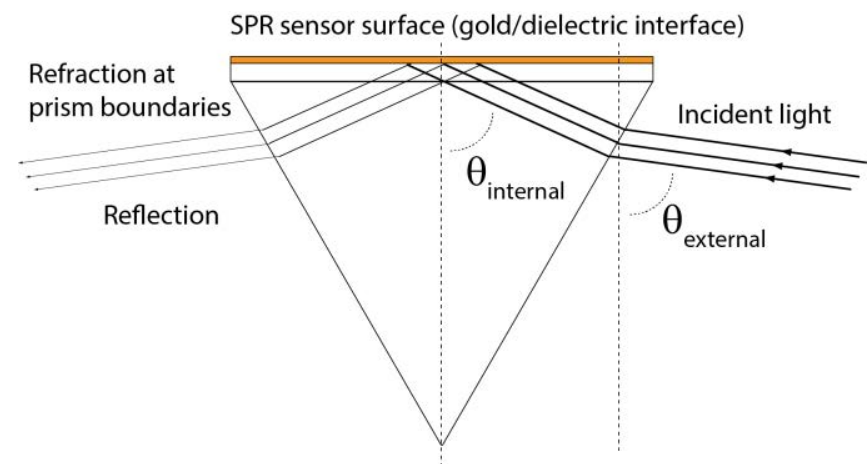

Figure 3.6: A schematic view of SPR sensor/prism configuration in iSPR setup. Adapted from Olof Andersson [94].

work [93].

\subsection{Imaging Surface Plasmon Resonance (iSPR)}

Surface plasmons exist at the gold/dielectric interface. Energy from incident light can be coupled into the surface plasmons at the resonance condition, if the angle of incidence (AOI) and wavelengths are appropriate. The resonance can be observed as a decrease in reflection from the surface under total reflection conditions. The change of resonance is followed in the minimum in the reflectance, by varying wavelength or AOI. From the resonance conditions, SPR wavelength $\left(\lambda_{S P R}\right)$ is determined. The change in $\lambda_{S P R}$ is used to calculate the mass change upon adsorption on the surfaces (see Paper I). The resonance condition is very sensitive to the changes in refractive index near the metal surface. The probing depth of SPR is determined by the penetration depth of the evanescent field, which is of the order of hundred nanometers [94]. The configuration of SPR surface and prism we used in iSPR is illustrated in Figure 3.6.

iSPR was used to follow protein adsorption (Paper I and II) in real-time. 
Chapter 3. Characterization methods

The instrumental configuration details, operating principles, data analysis and interpretation were described by Olof Andersson [94]. It is a tool that is commonly used to monitor biomolecular interactions on the sensor surface [47] (a thin gold film coated glass). The iSPR system used in our work has a CCD camera as an array detector to collect the reflectivity from the sensor surface in two dimension (XY), which we referred to as SPR images [94] in the papers. For instance, in the SPR images in Paper I, the Z axis in the map refers to the shift of the resonance wavelength in each pixel, calculated from the reflectivity curves measured by wavelength interrogation mode, where the SPR wavelength shifts towards longer wavelength with the protein adsorption.

\subsection{Optical analysis based on Metal Enhanced Fluorescence (MEF)}

Metal enhanced fluorescence uses the amplification of fluorescent emission by metallic substrates with nano structures, for studying the adsorbates near the plasmonic field. MEF substrates should be able to offer high plasmonic coupling to the excitation photons to enhance the fluorescence intensity, therefore matching the excitation wavelength of the fluorophore is important.

The MEF theory will be further described in Chapter 4. At certain close distances, quenching can be a problem in the vicinity of metal surfaces, as it is a non-radiative process involving energy transfer between fluorophores. To avoid emission quenching, tuning the distance $[95,96]$ between the particle and fluorophore is necessary to avoid quenching and to optimize the MEF effect (see Figure 3.7).

The optimum of separation between the plasmonic substrate and the dyes or molecules is determined by the Förster distance [97], which is typically in the range of a few nanometers. Depending on the interaction of plasmonic substrate and the targeting objects, one has to control some parameters to achieve the optimum, such as dye concentration, spacer thickness and particle density to avoid quenching and reaching high enhancement. 

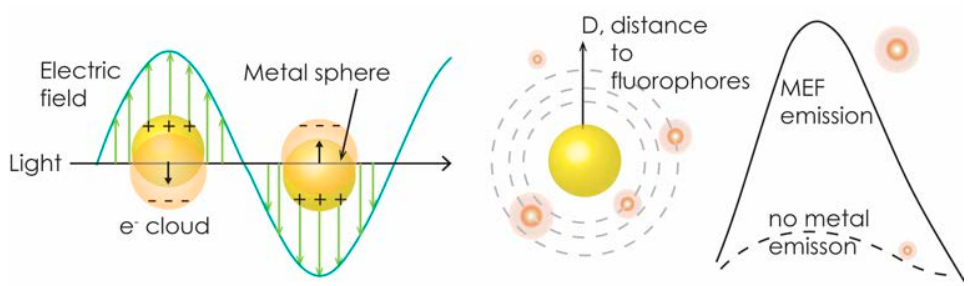

Figure 3.7: MEF is a plasmonic effect. The left sketch shows how the incident light excites the coupling of the plasmon, and the right sketch shows the variation in emission with distance, illustrating the enhancement effect.

The hydrogel MEF platform was used to find the optimum of the hydrogel thickness. The fluorescence images were captured before and after silver nanoparticles (AgNPs) were attached, and the difference in emission intensity can be easily distinguished (see Paper V).

Simultaneously, one spectrum was collected from each pixel on the image, which provides local information about the particle aggregation, and possibly the uniformity of the hydrogel film (together with the SEM images). The enhancement factor distribution on the surface can also be correlated the particle distribution.

\subsection{Scanning Electron Microscopy (SEM)}

Scanning electron microscopy (SEM) is a widely used imaging tool for length scales between a few hundred micrometer down to a few nanometers. The magnification range is usually between 10 to 500,000 times, and the depth of field can be between $\mu \mathrm{m}$ to $\mathrm{mm}$ (depending on the magnification, working distance and the aperture size), which is a great advantage compared to optical microscopy, where the depth of field is usually below $1 \mu \mathrm{m}$ at a magnification of 50 times, depending on the numerical aperture as well. This also makes the image look more three dimensional, similar to confocal images. Inelastic scattering of incident electrons from the sample results in secondary electrons emitted from the atoms near the surface [98]. These secondary electrons escaping from the surface layer are collected to generate topography 
Chapter 3. Characterization methods

images with a resolution of few nanometers. The elastically back scattered electrons, mostly reflection of the incident beam, are collected for creating composition contrast based on elemental difference (atomic number). The AgNPs attached to the hydrogel MEF platform have a diameter of $40 \mathrm{~nm}$, and are able to be resolved. The major limitation is that since the image is created from the electrons, non-conducting samples usually need to be coated with a thin gold layer to avoid the charging effect that distorts the image. Vacuum requirement for the electron beam is sometimes a limit for the samples which can evaporate continuously. The hydrogel films might contain certain moisture in their dry state, which will be pumped out during the vacuum pump step. Environmental SEM [99] is available for biological or non-conducting samples to be examined at lower vacuum and even with certain humidity. 
3.6. Scanning Electron Microscopy (SEM) 


\section{Chapter 4}

\section{Forces and interactions}

Surface properties are governed by interactions at the intermolecular or supramolecular level. In our hydrogel model systems studied in Paper I to IV, van der Waals forces, electrostatic double-layer forces, steric forces and hydrophobic forces are expected. Theses interactions are briefly explained in the following, and the general concepts of metal enhancement fluorescence is described, which was used in Paper V.

\subsection{Intermolecular and surface forces}

These forces often dominate the interactions in colloids [100] and play important roles in supramolecular chemistry. Some functions rely on the structures of biomolecules, and the structural formation are driven by these intermolecular forces [101]. For example, folding (secondary structures) of proteins involves hydrophobic and van der Waals forces, and hydrogen bond formation.

\subsubsection{Van der Waals force}

Van der Waals forces are short-range interactions between surfaces in colloidal systems. They could usually be observed close and prior to the contact occurs in the force curves. In Paper I to IV, we observed a weak attraction at small separations of the force curves in direct force measurements at the charge-balanced regions. The magnitude and range of these interactions at 
the small separations indicate that these were van der Waals forces, while the contribution of electrostatic and steric forces were small. The weak interactions originating from interacting permanent dipoles, induced dipoles (Debye force) and instantaneously induced dipoles (London dispersion force) are generally and collectively referred to as van der Waals forces. Dispersion forces are always present in the total van der Waals force, and can be significant in adhesion, surface tension and wetting. To describe the van der Waals forces between two microscopic objects, Hamaker approximation [102] was introduced for integrating the total energies of additive and non-retarded interatomic pair potentials of the form $w(r)=-\Phi / r^{6}$

The free energy of van der Waals interaction is calculated with different geometries in Hamaker's model. For instance, between two planar surfaces, $W=-A / 12 \pi D^{2}, D$ is the distance between two surfaces. The conventional Hamaker constant can be identified as: $A=\pi^{2} \Phi \rho_{1} \rho_{2}$,

where $\Phi$ is the coefficient of atom-atom pair potential, and $\rho_{1} \rho_{2}$ are the numbers of atoms per unit volume in the two objects.

A typical Hamaker constant is about $10^{-19}$ to $10^{-20} \mathrm{~J}$ depending on the materials. When estimating the surface charge and potential of the colloidal probes, a Hamaker constant we used is $4 \times 10^{-19} \mathrm{~J}$, ignoring retardation.

\subsubsection{Electrostatic double-layer forces between surfaces}

When the hydrogel gradients were probed by the colloidal AFM probe in buffers, the interaction between the charged probe and the gradient surface involves electrostatic double-layer forces. It was concluded in Paper I and II that the electrostatic interaction was the main contribution to the selective protein adsorption, and electrostatic double-layer forces are important for the interactions of proteins with surfaces. If we start with a surface in aqueous solution (as shown in Figure 4.1), it is almost always charged due to adsorbed free ions from the solution, and asymmetric dissociation of surface chemical groups, forming the surface charge layer. The Stern-layer refers to the compensating counterions, as the second layer of the electrical double-layer. The diffusion ion layer forms due to thermal motion and entropy gain when ions leave the Stern layer, but Coulomb attraction from the surface charges, the 


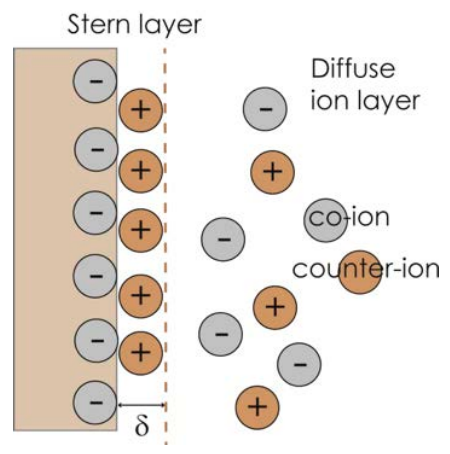

Figure 4.1: A negatively charged surface in an electrolyte solution with a double-layer formed. The Stern and diffuse ions form the outer layer together.

first layer, keeps them as a loosely associated layer (Stern Model, 1924).

\section{Poisson-Boltzmann (PB) equation and the Debye length}

Consider a charged surface with surface charge density $\sigma$ and potential $\psi_{0}$, in an electrolyte solution with co-ions and counter-ions, at bulk concentrations $C_{i}^{0}$, and dielectric constant $\varepsilon_{r}$. The early Gouy-Chapman Model (1910) assumed that the distribution of ions in the diffuse layer [100] follows Boltzmann distribution, in which the surface is assumed to have a uniform charge coverage, and the Stern layer is not considered: The Boltzmann distribution of ions of type $i$ at position $x$ from the surface is:

$C_{x i}=C_{i}^{0} e^{-z_{i} e \psi_{x} / k T}$, where $z_{i}$ is the valance of ions of type $i$.

Inserting this Boltzmann distribution into the Poisson equation to solve the potential of the electrical field yields:

$\nabla^{2} \psi=\frac{z e \rho}{-\varepsilon_{0} \varepsilon_{r}}$, where $\rho=\sum_{i} z_{i} e C_{x i}$,

results in the Poisson-Boltzmann (PB) equation describing the electrochemical potential in the diffuse ion layer: 


$$
\nabla^{2} \psi=-\sum_{i} z_{i} e C_{i}^{0} e^{-z_{i} e \psi / k T}
$$

When the geometry is a planar surface, the PB equation could be solved analytically [100] due to the symmetry that allows a one-dimensional solution. Assuming that the surface is in a symmetric electrolyte, $z_{i}=z_{+}=$ $z_{-}=z$ the second derivative form in $x$ is written as:

$$
\frac{d^{2} \psi}{d x^{2}}=\frac{2 c_{0} z e}{\varepsilon \varepsilon_{0}} \sinh \frac{z e \psi}{k T}
$$

Multiply both sides by $2 \frac{d \psi}{d x}$, and then integrate twice over $x$ from $\infty$ to $x=d$ (where the diffuse layer starts). Let $\psi(x=d)=\psi_{d}$, with the boundary conditions that the potential must go to zero in the bulk (as $x$ goes to $\infty$ ),

$\left.\frac{\mathrm{d} \psi}{\mathrm{d} x}\right|_{x \rightarrow \infty}=0$, we get $\tanh \frac{z e \psi}{4 k T}=\tanh \frac{z e \psi_{d}}{4 k T} e-{ }^{\kappa(x-d)}$,

that $\psi(x)=\frac{2 k T}{z e} \ln \left[\frac{1+e^{\kappa x} \tanh \frac{z e \psi_{d}}{4 k T}}{1-e^{\kappa x} \tanh \frac{z e \psi_{d}}{4 k T}}\right]$

For small potentials, $\tanh x \approx x$, and $\psi=\psi_{d} e^{-\kappa(x-d)}$, which is identical to the Debye-Hückel approximation.

Equation 4.1 is a mean-field approximation, and can be solved linearly with the Debye-Hückel approximation (1923), treating the ion interactions in dilute solutions with a simplified assumption, to determine the charge distribution [100]. If the electrical energy is small relative to the thermal energy, where $e|\psi| \ll k T$

We can use Taylor expansion that gives a linear PB equation (Debye-Hückel equation)

$$
\frac{d^{2} \psi}{d x^{2}} \approx-\frac{1}{\varepsilon \varepsilon_{0}}\left[-\frac{\psi}{k T} \sum z_{i}^{2} e^{2} C_{i}^{0}\right]=\frac{\sum z_{i}^{2} e^{2} C_{i}^{0}}{\varepsilon \varepsilon_{0} k T} \psi=\kappa^{2} \psi
$$

The solution is written as: $\psi(x)=\psi_{d} e^{-\kappa x}$, where $\kappa=\sqrt{\frac{\sum z_{i}^{2} e^{2} C_{i}^{0}}{\varepsilon \varepsilon_{0} k T}}\left[m^{-1}\right]$, 
is the Debye-Hückel parameter, and $\kappa^{-1}$ is the Debye length. The surface potential then becomes a simple exponential decay where the caracteristic decay length $\kappa^{-1}$. The Debye length $\kappa^{-1}$ determines how far the diffuse ion layer extends from the surface into the bulk. The surface potential is screened by the ions and decreased to $1 /$ e of its initial value at this distance from the surface. The decay length is only determined by the bulk concentration regardless the charge or potential on the surfaces.

$\kappa=\sqrt{\frac{e^{2} \Sigma_{i} z_{i}^{2} C_{i}^{0}}{\varepsilon_{0} \varepsilon_{r} k T}}, C_{i}^{0}$ is the bulk ion concentration of ion species $i$.

For example, at $298 \mathrm{~K}$, the Debye length is $\kappa^{-1}=\frac{0.304}{z\left[M_{0}\right]} \mathrm{nm}$, for a monovalent 1:1 electrolyte. $z$ is valency, $M_{0}$ is the bulk concentration. The Debye length of the buffer solution which we used for our hydrogel model systems, is about $3.04 \mathrm{~nm}$ (1 mM monovalant buffers).

\section{Grahame equation}

Stern (1924) and Grahame (1947) Model refined the Gouy-Chapman Model, to treat the compensating charge layer as a combination of a compact layer with a linear decay until the Stern Plane (see Figure 4.1), and a loosely associated diffuse layer beyond the Stern layer. The general relation between the surface charge density $\sigma$ and the total ion concentration at the surface can be written as:

$\sum_{i} C_{i}^{s}=\sum_{i} C_{i}^{0}+\sigma^{2} / 2 \varepsilon_{0} \varepsilon_{r} k T$, which is the Grahame equation [103].

The relation between surface charge density $\sigma$ and potential $\psi$ can also be written as:

$\sigma^{2}=2 \varepsilon_{0} \varepsilon_{r} k T\left(\sum_{i} C_{i}^{s}-\sum_{i} C_{i}^{0}\right), \quad \sigma=\sqrt{8 C_{0} \varepsilon \varepsilon_{0} k T} \sinh \left(\frac{e \psi}{2 k T}\right)$.

With a known ion concentration $\left(C_{1}\right.$ and $\left.C_{2}\right)$, it can be simplified to 
$\sigma=0.117 \sinh (\psi / 51.4)\left\{\left[C_{1}\right]+\left[C_{2}\right]\left(2+e^{-\psi / 25.7}\right)\right\}^{1 / 2}$,

where the ion concentrations are in $\mathrm{M}, \psi$ in $\mathrm{mV}$, and $\sigma$ in $\mathrm{Cm}^{-2}$. For $1: 1$ electrolyte solutions, the Grahame equation gives:

$\sigma=0.117 \sinh (\psi / 51.4) \sqrt{\left[C_{1}\right]+\left[C_{2}\right]}$

If divalent ions are present, the surface potential $\psi$ and the counterions at the negative surfaces will have significant changes. $\psi$ decreases with increasing concentration of divalent counterions. At the low potentials, the Grahame equation can be simplified as

$\sigma \approx \sqrt{8 C_{0} \varepsilon \varepsilon_{0} k T}\left(\frac{e \psi}{2 k T}\right)=\varepsilon_{0} \varepsilon_{r} \kappa \psi$, where $\kappa^{-1}$ is the Debye screening length.

\section{Charge regulation}

Ions on surfaces start interacting with each other across the intervening medium at short surface separations, which leads to charge regulation [100]. The surface charge cannot remain a constant as the distance of two surfaces decrease.

When $D \rightarrow 0$, the repulsive pressure at zero distance becomes: $P(D \rightarrow 0)=$ $-2 \sigma k T / z e D$, as $D$ is approaching zero, $\sigma$ becomes a function of $D$. This change in surface charge $\sigma$ with distance is known as charge regulation, which decreases the repulsion.

\section{Osmotic pressure between symmetric surfaces}

When two identical surfaces are brought to close at a distance $D$, the diffuse electric double layers overlap and result in the electrostatic double layer repulsion force. The excess osmotic pressure in the overlap region is used to describe the raising repulsion [100]. The pressure at the midplane between two charged surfaces in an 1:1 electrolyte can be written

$P=k T C_{i}^{0}\left[\left(e^{-e \psi_{m} / k T}-1\right)+\left(e^{+e \psi_{m} / k T}-1\right)\right] \approx e^{2} \psi_{m}^{2} C_{i}^{0} / k T$

which is a first order PB equation.

Assuming that the distance between two surfaces is large enough, the midplane potential $\psi_{m}$ is small, resulting in a weak interaction of the overlapped 
double-layers. The middle plane potential is the sum of the potentials from each surface at $x=\frac{1}{2} D, \frac{d \psi}{d x}=0, \psi=\psi_{m}$, that yields

$\psi_{m} \approx(8 k T \gamma / e) e^{-\kappa D / 2}$, where $\gamma=\tanh (z e \psi / 4 k T)$

Therefore the final repulsive pressure between two planar surfaces is

$P=64 k T C_{i}^{0} \gamma^{2} e^{-\kappa D}$

known as the weak overlap approximation. The total energy is then written

$W=\left(64 k T C_{i}^{0} \gamma^{2} / \kappa\right) e^{-\kappa D}$.

As seen in the above relation, the double-layer repulsion decays exponentially with the separation between surfaces, with the characteristic Debye length. This electrostatic repulsion is treated together with van der Waals forces in the DLVO theory.

\subsubsection{DLVO theory}

Derjaguin-Landau-Verwey-Overbeek (DLVO) theory [104,105], developed during the 1940s, describes the van der Waals and double-layer electrostatic force together. They are assumed to be independent and could be superimposed as functions of the separation between two colloidal particles in terms of repulsive and attractive potential. The colloidal stability is primarily determined by these two terms. The van der Waals interaction depends on the dielectric constant, and its magnitude always exceeds the double-layer repulsion at small separations. The electrostatic double-layer force profile strongly depends on the ion strength and the surface charge. The total DLVO interaction energy $W(D)$ between two spherical particles at constant potential (in the linear $\mathrm{PB}$ equation) is:

$W(D)=\left(64 \pi k T R C_{\infty} \gamma^{2} / \kappa^{2}\right) e^{-\kappa D}-A R / 6 D$. 


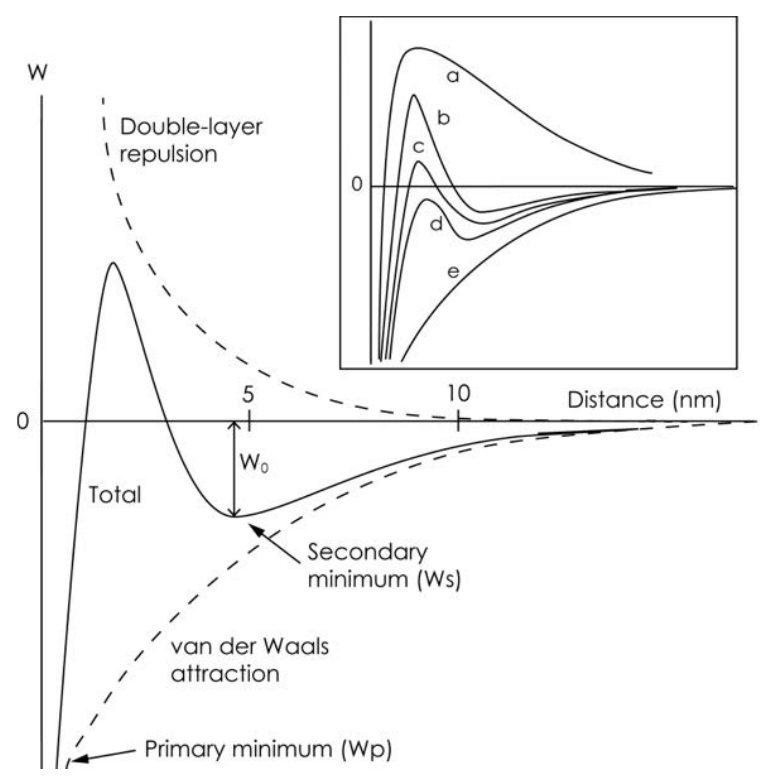

Figure 4.2: Energy diagram of DLVO interaction adapted from Israelachvili [100]. The energy vs. distance profile indicates the colloidal stability: (a) is a strongly repulsive system. (b) is kinetically stable (c) is close to coagulation. (d) is at the critical coagulation condition. (e) rapid coagulation. From (a) to (e), the bulk salt concentration increases and the surface potential decreases.

The second term is the van der Waals interaction for two interacting macroscopic spheres. The interaction energy is illustrated in Figure 4.2. In a dilute electrolyte, highly charged surfaces show long-range repulsion (curve a in Figure 4.2), and the energy barrier to coagulation is usually located between the separation of $1-4 \mathrm{~nm}$. The secondary minimum appears when the electrolyte concentration increases, the colloids stay dispersed, but are only kinetically stable (curve b), when the energy barrier is high. Lower surface charge or potential will result in a lower energy barrier before the primary minimum, and as the electrolyte concentration increases, the colloids start to aggregate in curve c. After the critical coagulation condition, where the total energy $W<0$ at the all distances, leads to rapid aggregation in curve d. If the surfaces interact solely with van der Waals force, the attraction dominates 
at all separations, as in curve e. DLVO gave remarkably good agreement to many experimental results $[87,100]$. At the small separations, non-DLVO forces, such as oscillatory solvation forces, structural force, hydration forces, and hydrophobic force could dominate the force curves instead.

DLVO is used in our model systems (See details in Paper III) to evaluate the electrostatic double-layer forces in the total force interactions.

\subsubsection{Hydration and hydrophobic forces}

\section{Hydration}

Strongly bound water molecules being expelled from the region between the surfaces is thought to be one origin of hydration forces, and has been experimentally verified [100]. Such a water structure is one of the important non-DLVO forces that could dominate at small separations in aqueous solutions [64]. There is also another perspective which suggests that the entropic repulsion [106] of thermally excited surface groups is the origin. Repulsive hydration force is often experimentally observed to decay monotonically at a distance of $3 \mathrm{~nm}$ [107]:

$F=F_{0} e^{-D / \lambda_{0}}$, where $F$ is the force, $\lambda_{0}$ is the decay length and $D$ is the separation while the repulsion is observed. The decay length and the magnitude of the force depend on the nature of the surface, or more specifically, the origin of its hydration force [100].

For zwitterionic materials, hydration is considered to be the foremost reason for their strong fouling resistance [35]. In the charge-balanced region of our hydrogel gradients, the films are highly compressed, and the steric repulsion is unlikely to give a major contribution to the fouling resistance. It appears likely that hydration is important. Hydration could possibly contribute to the total interaction between the hydrogels and the colloidal AFM probes, but at the short separation below $3 \mathrm{~nm}$, it is uncertain to conclude the presence of hydration repulsion in our hydrogels.

\section{Hydrophobic interaction}

Hydrophobic groups tend to avoid contact with water molecules in aqueous solutions, thus the hydrophobic (non-polar) groups aggregate to min- 
imize the surface area exposed to water [108] and leads to aggregation or phase separation. Hydrophobic interaction is an important driving force for protein folding and self-assembly [109], it could also result in nonspecific binding [110]. Hydrophobic attraction is in general stronger than van der Waals forces [100]. Nevertheless, the hydrophobic interaction disrupts the hydrogen-bond network in water, and locks the water molecules into an entropically unfavourable structure. Such an interaction might occur within the hydrogels due to the polarity difference in the polymer structure.

\subsubsection{Steric forces}

Steric forces are expected to be involved in the total interactions between the hydrogel films and the proteins, as well the colloidal probes, which depend on the structure of the polymers. A classic example is the protein resistance of poly(ethylene glycol), PEG-containing polymers [18,81]. The mechanism of resistance is not only due to the charge neutrality, the steric repulsion from the long PEG chains $[31,32,62]$ and the strong hydration from water molecules [30,33,61,65] also contribute significantly. Steric forces also have a great importance for stabilization [100] of colloidal systems. Particles coated with polymers, whether grafted or adsorbed, can remain dispersed in medium by steric repulsion that prevents aggregation. For our hydrogel films, steric forces were expected and thought to be related to the polymer network swelling. Steric repulsion raises from compression of long chains, while the segments start to overlap, and reaching volume restriction [100]. Grafted neutral brushes are quite well described by Alexander de Gennes theory (AdG) [76,77], and it is further extended for polyelectrolyte systems by Kamiyama and Israelachvili [111], and later modified by Dunlop et al. [78]. The hydrogel films in our work had a complex structure compared to brushes, and the degree of cross-linking still remains to be investigated. In Paper III, we have tried to fit the force data of P(MAA-DMAEMA) hydrogel films with few possible models, but still were not able to unequivocally distinguish the steric repulsion from electrostatic contribution. Though it is clear that the steric forces dominate in the long range at distances beyond the Debye lengh on both sides of the gradient, where the swelling is significant. 


\subsection{Adhesion}

Adhesion is an energy required to separate two surfaces from each other when they are in contact. The early Hertz theory (1881) described an elastic deformation that yields a contact radius when a compressing force is in present, but not taking the adhesion into account. JKR [112] proposed an adhesion area instead and treated the adhesion as a surface energy existing without an external force applied. DMT theory $[113,114]$ treated both the contact adhesion and also the attractive force between the surfaces (see Figure 4.4). Two perfect spheres have an infinitely small contact point, and when they are allowed to deform, to separate in a medium, the energy is

$W_{132}=W_{12}+W_{33}-W_{13}-W_{23}=\gamma_{13}+\gamma_{23}-\gamma_{12}$,

while $\gamma_{1}$ and $\gamma_{2}$ are the surface energies for the new surfaces after cleavage, and $\gamma_{12}$ is the interfacial energy.

$W_{12}=\gamma_{1}+\gamma_{2}-\gamma_{12}$ (see Figure 4.3) The pulling force between two spheres with elastic deformation in contact and adhesion (see Figure 4.3) is:

$F=2 \pi\left(\frac{R_{1} R_{2}}{R_{1}+R_{2}}\right) W_{132}$

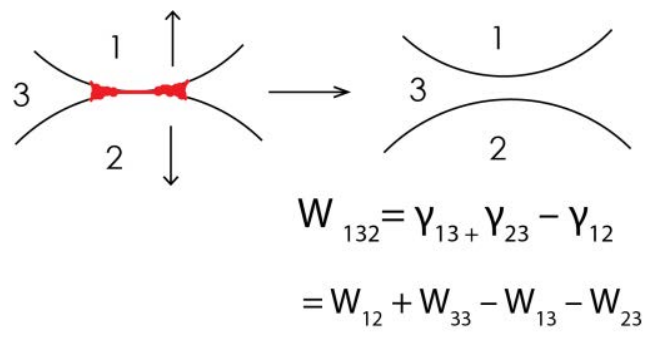

Figure 4.3: Adhesion sketch showing that of two unequal spheres, 1 and 2, being separated in a medium $3 . W_{123}$ is the energy to split surface 1 and 2 in medium 3. $\gamma_{12}$ is the interfacial energy.

In reality, the deformable spheres have a contact radius with surfaces even under zero external loads. JKR theory by Johnson, Kendall and Roberts 
(1971) solved this with rigorous treatment [112]. Two spheres with radius $R_{1}$ and $R_{2}$, elastic moduli $K$, and surface energy $W_{12}$, will adhere to each other under the external force $F$, and the contact area has a radius $a$ :

$a^{3}=\frac{R}{K}\left[F+3 \pi R W_{12}+\sqrt{6 \pi R F W_{12}+\left(3 \pi R W_{12}\right)^{2}}\right]$,

where $R=R_{1} R_{2} / R_{1}+R_{2}$

At the external force $F$, the two surfaces adhere until reaching a critical pulling force. This force is the pull-off force:

$F_{s}=-3 \pi R \gamma_{S V}$, where $\gamma_{S V}=\frac{W_{12}}{2}$

If a particle with radius $R$ contacts with a flat surface of the same material, the contact radius at pull-off becomes: $a_{s}=a_{0} / \sqrt[3]{4}=0.63 a_{0}$

At the limit of small deformations, the adhesion force changes from JKR limit, $3 \pi R \gamma$, to DMT limit [113,114], $F_{s}=-4 \pi R \gamma$, by Derjaguin-MullerToporov theory, due to the breakdown of continuum assumption in JKR theory that allows attractive force acting only over infinitely small range $[113,114]$.

Hertz Theory

JKR Theory

DMT Theory
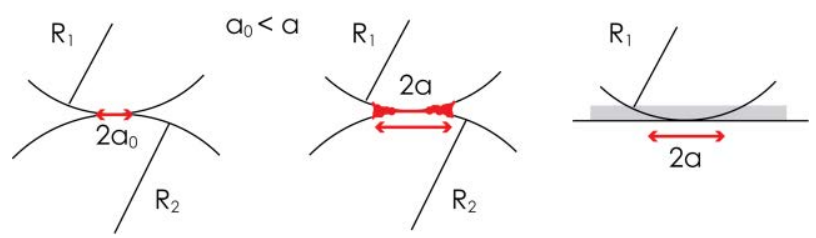

Figure 4.4: Comparison between Hertz contact and JKR, DMT adhesion. JKR treated adhesion (red area), and DMT included the attraction between two surfaces (gray area). 


\subsection{Biomolecular interactions}

Biomolecular interactions can be either specific or non-specific. Specific biomolecular interactions always have well-defined recognition, such as antibody binding. In contrast, the non-specific interactions undergo similar processes but without specified targets, for instance protein adsorbing to artificial surfaces $[1,16]$. In this thesis, the hydrogel coatings in Paper I and II, were made for investigating the protein resistance of charge-balanced polyelectrolytes, based on the protein adsorption profile along the hydrogel gradients. The dominating factor for the protein adsorption is the electrostatic force between the hydrogels and the proteins: proteins adsorbed selectively onto the oppositely charged hydrogels, and desorbed when the surface charge changes on the hydrogel gradients. The least adsorption occurs where the net charge is nearly zero, and the electrostatic force is minimized. Protein adsorption is an important early-step for biofouling [18], and to investigate how the fouling resistance and the surface properties of the hydrogels affect the protein adsorption is in our interest. It is still worth to mention hydration and hydrophobic force here, though in our system, we were not able to determine them from the force curves.

\subsection{Metal enhanced fluorescence}

To demonstrate a platform for MEF, a hydrogel film was fabricated and used as a spacer between the fluorophores $\left(\mathrm{Ru}(\mathrm{BPY})_{3}\right.$, Tris $\left(2,2^{\prime}\right.$-bipyridyl $)$ dichlororuthenium(II) hexahydrate), and the spherical silver nanoparticles (diameter of $40 \mathrm{~nm}$ ), see details in Paper V. Metal enhanced fluorescence (MEF) is an example of plasmonic effect [115]: while coupling occurs between the incident light and the excited collective oscillation of the electron cloud on metal particles. The excited fluorophores interact with surface Plasmon of metal surfaces, resulting strong enhancement of the fluorescence emission [97]. MEF was firstly observed on rough metal surfaces [116, 117], and as development on going, many types of nanoparticles (shape, size, material, core-shell structure) are reported to achieve high enhancement [118-122]. Free-space fluorescence is not an instantaneous process which progresses over 


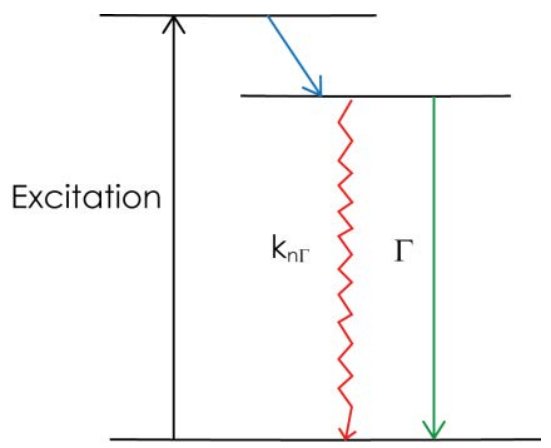

Figure 4.5: Simplified Joblonski diagram of fluorescence. $\Gamma$ is the intrinsic decay that leads to emission, while $k_{n r}$ is non-radiative decay which does not emit photons. Fluorescence process involves electronic transition, relaxation and emission [97].

time: the absorbed photons excite the electrons to the excited states, and then undergo internal conversion, finally relax back to the ground state and result in emission. The optical process is illustrated in Figure 4.5. In MEF, the photon absorption is enlarged by the plasmonic coupling, and the radiative decay route is proposed to have an energy transfer involving the plasmonic states, which differs from the free-space emission [123, 124].

The relaxation can also go through non-radiative process, which does not emit photons, as shown in the Figure $4.5, k_{n r}$, the non-radiative decay. A large amount of experimental and theoretical work has been done to explain and predict MEF mechanisms, and it is proposed to be an association with the strong near field resulting from the localized surface plasmon resonance (LSPR) [125]. The mechanisms of MEF are still debated and yet fully understood $[97,123,124]$. Though the mechanisms remain to be answered, the general concept of MEF have been demonstrated in many examples for biosensors [126]. Figure 4.6 shows the MEF process as described above.

MEF is found particularly pronounced on silver NPs, as used in Paper V. It is known that the photon absorption is expected to lead to quenching while the scattering results in enhancement [123]. Thus NPs with larger size are thought to be favorable for MEF. Quenching of the fluorescence has 


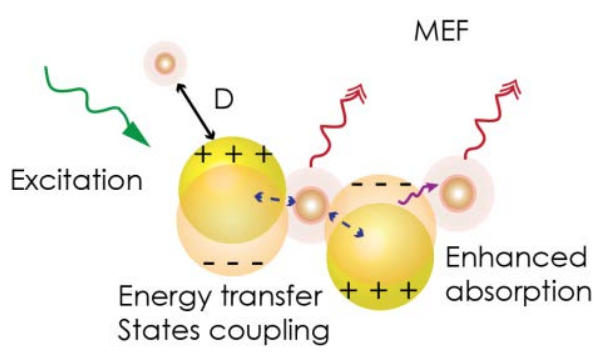

Figure 4.6: The illustration of general concepts of MEF $[123,124]$ : enhanced absorption by local electromagnetic field, and the coupling of excited flourophores and the plasmonic states. $D$ is the distance that MEF effect is not valid anymore (far field emission)

significant reduce of emission intensity. Quenching occurs either when the plasmonic coupling cannot go through radiation which is limited by interface optical continuity, or the energy transfer undergos non-radiative relaxation. Most quenching examples were found in gold NPs [95], and when the fluorophores contact directly with metal [96]. MEF can be optimized by choosing the combination of plasmonic structure and the fluorophores, and optimized by the distance between the NPs and the fluorophores. Optimized distance were studied and found to be independent in different systems [127-131]. 
4.4. Metal enhanced fluorescence 


\section{Chapter 5}

\section{Summary of the results and the included papers}

The studied polymer systems in this thesis are summarized in the following table. The notation $\mathrm{P}(\mathrm{A}-\mathrm{B})$ means that a thickness gradient using monomer $\mathrm{B}$ was grafted onto a layer of homogeneous thickness prepared from A:

\begin{tabular}{|c|c|c|}
\hline Paper & Coating type & Content \\
\hline I & $\begin{array}{l}\mathrm{P}(\mathrm{AEMA}-\mathrm{CEA}) \\
\text { Hydrogel gradient }\end{array}$ & $\begin{array}{l}\text { Selective protein adsorption } \\
\text { and observation of resistance in } \\
\text { the charge-neutral region }\end{array}$ \\
\hline II & $\begin{array}{l}\mathrm{P}(\text { AEMA-CEA }) \\
\mathrm{P}(\mathrm{CEA}-\mathrm{AEMA}) \\
\text { Hydrogel gradients }\end{array}$ & $\begin{array}{l}\text { pH-regulated selective protein } \\
\text { adsorption and re-location of } \\
\text { the charge-neutral region }\end{array}$ \\
\hline III & $\begin{array}{l}\text { P(MAA-DAEMA) } \\
\text { Hydrogel gradient }\end{array}$ & $\begin{array}{l}\text { Investigation of interaction } \\
\text { forces with the charged gradi- } \\
\text { ent }\end{array}$ \\
\hline IV & $\begin{array}{l}\text { P(MAA-DAEMA) } \\
\text { Hydrogel gradient }\end{array}$ & $\begin{array}{l}\text { Hydrogel gradient patterned as } \\
\text { microarray spots }\end{array}$ \\
\hline $\mathrm{V}$ & $\begin{array}{l}\mathrm{P}(\mathrm{AEMA}-c o-\mathrm{HEMA}) \\
\text { Hydrogel films }\end{array}$ & $\begin{array}{l}\text { As a thickness-tunable spacer } \\
\text { for a MEF platform }\end{array}$ \\
\hline Appendix & $\begin{array}{l}\left(\mathrm{C}_{16} \mathrm{NH}_{2} / \mathrm{C}_{15} \mathrm{COOH}\right) \\
\text { Mixed SAMs }\end{array}$ & $\begin{array}{l}\text { Measurement of surface charges } \\
\text { on a rigid } 2 \mathrm{D} \text { surface exposing } \\
\text { primary amines and carboxylic } \\
\text { acids }\end{array}$ \\
\hline
\end{tabular}


The table above shows the footprint of the studies in this thesis and the main contents are highlighted in each paper. The research progress and relations between papers will be explained in the following text.

In Paper I to IV, two combinations of hydrogel gradients were studied as the model systems. The investigations of these gradients were designed to explore the properties of charge-neutral ampholytic polymers. The protein adsorption and interaction forces with these gradients were studied, and additionally, a patterned gradient was studied. In Paper V, a copolymerized hydrogel was applied to a MEF platform. It is an extension of the previous work, but where we used the knowledge about the hydrogels for controlling the MEF parameters, such as particle coverage and the spacer thickness.

In the Appendix, a series of mixed $\left(\mathrm{C}_{16} \mathrm{NH}_{2} / \mathrm{C}_{15} \mathrm{COOH}\right)$ SAMs were made from solution immobilization. The purpose is to study an ampholytic system with weak acids and bases, considered as a model for a surface where the locations of the charges were fixed at the interface, and not changing their distribution upon swelling (in contrast to the hydrogels). We then tried to fit with possible surface potential limits that gave a quantitative estimate of the electrostatic interaction.

\section{Paper I}

\section{Lateral Control of Protein Adsorption on Charged Polymer Gradients}

Tobias Ekblad, Olof Andersson, Feng-I Tai, Thomas Ederth and Bo Liedberg Langmuir, 2009, 25, 3755-3762

The hydrogel gradient $\mathrm{P}(\mathrm{AEMA}-\mathrm{CEA})$, consisting of a thickness gradient layer of PCEA, poly(2-carboxyethylacrylate) grafted on an oppositely charged bottom layer of PAEMA, poly(2-aminoethyl methacrylate hydrochloride) with a constant thickness, was fabricated by the SIPGP method. The intention of creating such a polyampholytic gradient, as originally suggested by Tobias Ekblad, was to monitor the protein resistance along the gradients, with an expectation that this bi-layered type of hydrogel coatings will behave 
Chapter 5. Summary of the results and the included papers

like the zwitterionic materials: it would result in a region where the charges were balanced, and that this region would show a minimum in protein adsorption. While selective protein adsorption by the opposite surface charge was also found on both ends of the gradient. Such polyampholytic gradients gave excellent demonstration of protein resistance due to charge-balance, though practically it is difficult to ensure the right ratio or thicknesses of two oppositely charged, and sequentially polymerized polyelectrolytes that can be applied as general protein-resistant coatings, a problem which was overcome by using a thickness gradient, where a large range of thickness or mass ratios were studied on the same sample. The significance of this work is that we were able to correlate the protein adsorption profile to the surface charge on the hydrogel gradients by IR microscopy, real-time iSPR and direct force measurement, which then became an opening for further investigation regarding the swelling and surface charge properties on these SIPGP polyampholyte hydrogel films.

\section{Paper II}

pH-Control of the Protein Resistance of Thin Hydrogel Gradient Films

Feng-I Tai, Olof Sterner, Olof Andersson, Tobias Ekblad and Thomas Ederth Soft Matter, 2014, 10, 5955-5964

Paper II is an extension of Paper I. The gradients studied here were $\mathrm{P}$ (AEMA-CEA), as in Paper I, and $\mathrm{P}(\mathrm{CEA}-\mathrm{AEMA})$, which is the reversed version. In this paper we demonstrated that the surface charges on these polyampholytic gradients are $\mathrm{pH}$ dependent, which is expected as the two layers form weak polyelectrolytes. It is found that the minimum protein adsorption position moves along the gradients in response to $\mathrm{pH}$ changes, and the protein adsorption profiles changed in response to the changing the electrostatic interaction. The relocation of the protein resistant area, the neutral region, was monitored by iSPR in real-time, and found to correlate with the surface charge obtained from the force curves. The force curves identified the surface charges on the gradients and helped to clarify the protein readsorption or fall-off via $\mathrm{pH}$ change in the iSPR map. The two gradients 
are found not to behave symmetrically and their swelling differs from each other quite a lot. This indicates that the ionization of two hydrogels could be different, and the polymer structure of such bi-layered gradients cannot be simply described as a homogeneous network. In this work, we demonstrated the $\mathrm{pH}$ dependence of the charge-balance in this polyampholytic hydrogel system, and it is observed in the force interactions and the protein adsorption. The experience and concept in this work could hopefully contribute to the future design or manipulation of antifouling coatings.

\section{Paper III}

Interaction Forces on Polyampholytic Hydrogel Gradient Surfaces Feng-I Tai, Olof Sterner, Olof Andersson, Tobias Ekblad and Thoams Ederth ACS Omega, 2019, 4, 5670-5681

When our study moved forward, it became clear that understanding the interaction forces between these polyampholytic hydrogel films and the proteins (or probes) was necessary to answer the further questions of their polymer structure, and the charge distribution within the polymers. We decided to use P(MAA-DMAEMA), poly(2-dimethylaminoethyl methacrylate) on a poly(methacrylic acid) gradient here for a surface force and swelling study, because both DMAEMA and MAA are well studied polymers, and we were also interested in extending the work in Paper I and II to a different polymer system to assess the universality of the observed phenomena. Direct force measurement was used as the primary tool, and with complementary information from spectroscopic ellipsometry and infrared microspectroscopy, we demonstrate that charge-balanced regions can be formed in other SIPGP polymer systems than the ones made in Paper I and II. The interactions both within the polymer layers, and with the external AFM probe is a complex combination of steric and electrostatic interactions which vary in a nontrivial manner along the gradient, and it is not possible to unambiguously separate these contributions from the obtained force curves. However, we found that swelling and charging of the polymers are related and work in combination to yield the charge-balanced region, and that the charge-balanced region with high protein-resistance, is highly compressed, and that the resis- 
Chapter 5. Summary of the results and the included papers

tance to non-specific fouling thus most likely is a result of strong hydration at the surface rather than swelling or bulk hydration of the polymer. The fact that the salted brush models did not result in realistic fits to the data indicates that these SIPGP hydrogels hydrogels most likely are not brushes, but presumably have a cross-linked polymer structure in which the density and elasticity are underestimated if compared to polyelectrolyte brushes. This work provides information of relevance to fundamental studies of polyelectrolyte interactions and polymer thin film preparation, but it should also be of interest to the community developing zwitterionic and charge-balanced polymers for antifouling purposes.

\section{Paper IV}

\section{Spot-Patterned Hydrogel Gradients}

Feng-I Tai, Olof Sterner and Thomas Ederth

In manuscript.

It has been demonstrated in our previous works that the SIPGP hydrogels can be patterned in different geometries down to micrometer length scales for biomedical and biosenor applications. Here, a PDMAEMA gradient was patterned as spots on top of a uniform PMAA layer, with the thicknesses of the spots following the gradient growth direction as expected. The spots have a well-defined round shape, which benefits imaging, roughness and thickness characterization by AFM. This made it possible to be able to compare the properties of bi-layered hydrogels from the AFM images both in dry and wet state. This is also an excellent opportunity to compare AFM and ellipsometric thickness measurements. The force curves obtained on the spots are also consistent with those obtained on the the continuous gradient in Paper III. The charge balanced position moved from one spot to another when the $\mathrm{pH}$ value changed. The spots look much more dilute and rougher in wet state compared to in dry state in the AFM images. The accurate thicknesses of the spots in wet state are more difficult to model from the ellipsometry data due to the swelling, where the contrast between a dilute spot area and the matrix became less defined. The increased surface roughness increases the noise, and thus also the errors in the fitting. The thicknesses of dry spots 
measured by both AFM and ellipsometry are in good agreement, while they deviate significantly in the wet state. This might be explained by how a negatively charged tip gets in contact with a positively charged hydrogels, the attraction could pull up the hydrogel, and the pull-off distance will give a more extended volume than the real swelling (counted from the substrate surface). However, the refractive index change is related to the polymer density, and the modeled wet thicknesses were calculated from an assumption of a homogeneous layer when modelling the ellipsometry data. A realistic swelling thickness will rely on a more complex model that treats the polymer layers with a continuous variation of the polymer density. Both results from AFM and ellipsometry show qualitative agreement in terms of the trend of the thickness profile against gradient position.

\section{Paper V}

\section{Hydrogel Films as Spacers for Optimization of Metal Enhanced Fluorescence}

Feng-I Tai, Daniel Sjölander, Erik Martinsson and Daniel Aili In manuscript.

There is a great interest in using hydrogels for sensing purposes, so Paper $\mathbf{V}$ is an application where we used the knowledge about hydrogel charge properties studied in the previous papers. In this work, hydrogel spacers were fabricated for a MEF platform. Hydrogel films of P(AEMA-co-HEMA), (2-aminoethyl methacrylate hydrochloride-co-2-hydroxyethyl methacrylate) was fabricated by SIPGP as spacer layers to tune the distance between the silver nanoparticles and the fluorophores, until the MEF effect was optimized. The configuration of this MEF platform was formed by immobilizing the fluorophores on glass substrates, and then grafting a layer of hydrogel film on top of this, before adsorbing the AgNPs. Since electrostatic forces dominated the interaction between hydrogels and the approaching objects, studied in Papers I to III (proteins or collodial probes), the idea was to use the positive surface charges in the hydrogel films, to adsorb the AgNPs which were protected by negatively charged citrate groups. Depending on the type of nanoparticles to be adsorbed, the hydrogel platform is flexible 
Chapter 5. Summary of the results and the included papers

and have different monomer options. Though the risk of UV bleaching of the fluorophores incorporated into the layer beneath the hydrogel, due to the SIPGP process, cannot be avoided, the results showed that the enhancement is still significant in the tested spacer thickness range $(5-22 \mathrm{~nm})$. The spacer thickness is then easily determined regardless of the shape and size of the NPs. PHEMA was introduced to be copolymerized with PAEMA at the optimized mixing ratio (few ratios were tested) for improving the uniformity and stabilizing the films of various thicknesses. This platform was evaluated by fluorescence microscopy with a spectrometer to record both the images and spectra simultaneously. Three different thicknesses were decided to be used, from 7 to $17 \mathrm{~nm}$ by UV exposure from $2 \mathrm{~min}$ to $4 \mathrm{~min}$. The surface coverage of $\mathrm{Ag}$ nanoparticle was verified by using different incubation time in the AgNP solution and evaluated in SEM. The results showed that the optimum MEF has strong dependence on the spacer thickness and the particle density. To further improve the specificity in a biosensing application, the particles can be provided with handles for the analytes, which bind to the ligands in biosensing systems.

\section{Appendix}

The surface charge of two-component mixed self-assembled monolayers

In the Appendix, a series of SAMs from mixtures of 16-mercaptohexadecanoic acid (HS- $\left(\mathrm{CH}_{2}\right)_{15}-\mathrm{COOH}$, henceforth referred to as $\mathrm{COOH}$ or MHAc) and 16mercaptohexadecylamine (HS- $\left(\mathrm{CH}_{2}\right)_{16}-\mathrm{NH}_{2}$, referred to as $\mathrm{NH}_{2}$ or MHAm) were prepared, with the aim to produce a system where the net surface charge could be varied in a controlled manner by tuning the $\mathrm{pH}$, but without the added complexity of a swelling polymer. And to characterize the surface charge in relation to the mixture ratio of the formed SAMs by direct force measurements, using colloidal probe AFM. This was a separate topic raised from the studies in Paper I and II, in which we were not able to determine an exact ratio of two polymers at the charge balanced region. In mixtures of oppositely charged groups it is commonly observed that the surface ratio of the two components very often ends up being 1:1, irrespective of the solu- 
tion composition, due to electrostatic association of the oppositely charged residues during formation of the monolayer.

For preparing robust zwitterionic SAMs from mixtures of ionizable alkylthiols, the strength of the charged residues is of particular importance. The variations between solution and surface composition in mixed SAMs from charged thiols have been studied in several systems, but considerably fewer studies have characterized the resulting surface charge. The surface characterization showed that both types of functional groups were present in the mixtures, forming SAMs without packing disorder or segregation at all tested mixing ratios. Surface force measurement found that $\mathrm{NH}_{2}$ groups are weakly charged in comparison to $\mathrm{COOH}$ groups.

This considerable asymmetry prevented a systematic and consistent estimation of the surface charges, and the goal, to link the net surface charge on the surface to the composition, could not be met. For the hydrogels in Paper III, the dominant forces in the P(MAA-DMAEMA) system were steric interactions at locations far from the charge neutral region, and the net charge of the probe is not a probe of the polymer composition, but the failure to link the charge to composition remains a problem at other parts of the gradients where the polymer is less swollen. 


\section{Chapter 6}

\section{Future outlook}

\section{SIPGP polyampholyte hydrogel gradients}

The hydrogel gradients studied in this thesis, do provide insights into fundamental issues in polymer science, antifouling and charge regulation. The model hydrogels were useful for exploring the response of such a chargebalanced system, under varying environmental conditions. This is essential information for successful use of these in complex and high-salinity media, for instance, physiological conditions, blood, or seawater. However, applying a bi-layered coating to surfaces to achieve charge neutrality is a difficult approach, and not suitable to be transferred directly to practical coatings. Considering also the complexity of these hydrogels (in terms of polymer structures, and the properties that are unknown, or difficult to determine), they are probably only useful for specific purposes.

\section{SIPGP method and its potential}

The flexibility and versatility of the SIPGP method make its future potential promising. Compared to more well-controlled systhesis methods, such as ATRP (atom transfer radical polymerization ) or RAFT (reversible addition fragmentation chain transfer), it can be easily and quickly used for preparing polymers on almost any organic substrates, without initiators or catalysts. Patterning and adapting to different geometries are also straightforward. From a manufacturing perspective, a scale-up, production process, should be possible for such a simple method that is similar to UV curing. There 
are already many printed polymer devices available, and more are on their way in three dimensions, especially those for biomedical purposes. Printing strategy looks not far from practical for SIPGP polymers. For production of antifouling coatings, this can be a potential development.

The attempt of testing the hydrogels as spacers for MEF is an example for research or laboratory use. patterning an assay for sensing could a possible next step. SIPGP offers one to design and fabricate functional polymers in an easy manner, and it is not only for proof of concept, it has shown a potential for practical use. 


\section{Acknowledgments}

During the years of my $\mathrm{PhD}$ study, looking ahead and keeping every step moving forward has been the unchangeable goal. But here, the flashed back memories remind me how much I would like to thank the people who helped and supported me in this journey.

My supervisor Thomas Ederth, who guided me through the years to become a real scientist. I am very grateful for being given the freedom to explore my own interest, and always receiving challenges and feedback that pushed me forward.

I would like to thank Bo Liedberg, who opened up this adventure for me to begin.

Daniel Aili, who worked with me from day one to the last. I appreciate the patience and great input from you during the while time.

Stefan Klintstöm, thank you for being supportive all the time, and the great experience in Forum Scientium.

I would like to thank all the people I collaborated with in this work. Tobias Ekblad, thank you for introducing the hydrogels to me, and working with you was an encouraging experience. Olof Andersson, thank you for demonstration of iSPR, and all the other practical tips I need in the $\mathrm{PhD}$ student life. Olof Stener, thank you for the great work of ellipsometry, and the team effort was fantastic with your support. Erik Martinsson, thank you for sharing the knowledge about plasmonics and great discussions.

I could not mention all the names of the colleagues in Molecular physics group and the colleagues, friends in the department. You may not think that this acknowledgement is made specially for you, but it is specially for every of you, who I want to thank and not just thank. 
I also would like to thank all my colleagues at Hot Disk AB and Kagaku Analys AB. Lars Hälldahl and Henrik Otterberg, without the support and encouragement from you two, I would not be able to walk this far.

Finally, thank my family for being there for me, and my daughters who inspired me in many aspects.

I have more than thank to say to my husband Yuan-Chih, for accompanying me through this journey. The late nights we spent to discuss quantum mechanics, group theory for spectra interpretation, and how to turn our scientific concepts or ideas into graphical expressions, was one of the best part in these years. Thank you for everything.

Feng-I 


\section{Bibliography}

[1] David G Castner and Buddy D Ratner. Biomedical surface science: Foundations to frontiers. Surface Science, 500(1-3):28-60, 2002.

[2] Larry L Hench and Julia M Polak. Third-generation biomedical materials. Science, 295(5557):1014-1017, 2002.

[3] Ryan L Truby and Jennifer A Lewis. Printing soft matter in three dimensions. Nature, 540(7633):371, 2016.

[4] Ilya Levental, Penelope C Georges, and Paul A Janmey. Soft biological materials and their impact on cell function. Soft Matter, 3(3):299-306, 2007.

[5] Elodie Soussan, Stephanie Cassel, Muriel Blanzat, and Isabelle Rico-Lattes. Drug delivery by soft matter: matrix and vesicular carriers. Angewandte Chemie International Edition, 48(2):274-288, 2009.

[6] I Armentano, M Dottori, E Fortunati, S Mattioli, and J M Kenny. Biodegradable polymer matrix nanocomposites for tissue engineering: A review. Polymer Degradation and Stability, 95(11):2126-2146, 2010.

[7] S Ramakrishna, J Mayer, E Wintermantel, and Kam W Leong. Biomedical applications of polymer-composite materials: A review. Composites Science and Technology, 61(9):1189-1224, 2001.

[8] Sandra Pina, Joaquim M Oliveira, and Rui L Reis. Natural-based nanocomposites for bone tissue engineering and regenerative medicine: A review. Advanced Materials, 27(7):1143-1169, 2015.

[9] Enrica Caló and Vitaliy V Khutoryanskiy. Biomedical applications of hydrogels: A review of patents and commercial products. European Polymer Journal, 65:252-267, 2015.

[10] Allan S Hoffman. Hydrogels for biomedical applications. Advanced Drug Delivery Reviews, 64:18-23, 2012.

[11] Dror Seliktar. Designing cell-compatible hydrogels for biomedical applications. Science, 336(6085):1124-1128, 2012.

[12] Paul C Nicolson and Jürgen Vogt. Soft contact lens polymers: An evolution. Biomaterials, 22(24):3273-3283, 2001. 
[13] Paola Appendini and Joseph H Hotchkiss. Review of antimicrobial food packaging. Innovative Food Science \& Emerging Technologies, 3(2):113-126, 2002 .

[14] Zhenping Cheng, Xinlin Zhu, Z L Shi, K G Neoh, and E T Kang. Polymer microspheres with permanent antibacterial surface from surface-initiated atom transfer radical polymerization. Industrial $\& 5$ Engineering Chemistry Research, 44(18):7098-7104, 2005.

[15] Neethu Ninan, Aurelien Forget, V Prasad Shastri, Nicolas H Voelcker, and Anton Blencowe. Antibacterial and anti-inflammatory $\mathrm{pH}$-responsive tannic acid-carboxylated agarose composite hydrogels for wound healing. ACS Applied Materials 83 Interfaces, 8(42):28511-28521, 2016.

[16] Lei Zhang, Zhiqiang Cao, Tao Bai, Louisa Carr, Jean-Rene Ella-Menye, Colleen Irvin, Buddy D Ratner, and Shaoyi Jiang. Zwitterionic hydrogels implanted in mice resist the foreign-body reaction. Nature Biotechnology, 31(6):553, 2013.

[17] Indrani Banerjee, Ravindra C Pangule, and Ravi S Kane. Antifouling coatings: Recent developments in the design of surfaces that prevent fouling by proteins, bacteria, and marine organisms. Advanced Materials, 23(6):690$718,2011$.

[18] Tobias Ekblad, Gunnar Bergström, Thomas Ederth, Sheelagh L. Conlan, Robert Mutton, Anthony S. Clare, Su Wang, Yunli Liu, Qi Zhao, Fraddry D'Souza, Glen T. Donnelly, Peter R. Willemsen, Michala E. Pettitt, Maureen E. Callow, James A. Callow, and Bo Liedberg. Poly (ethylene glycol)containing hydrogel surfaces for antifouling applications in marine and freshwater environments. Biomacromolecules, 9(10):2775-2783, 2008.

[19] Shaoyi Jiang and Zhiqiang Cao. Ultralow-fouling, functionalizable, and hydrolyzable zwitterionic materials and their derivatives for biological applications. Advanced Materials, 22(9):920-932, 2010.

[20] Andreas Larsson, Tobias Ekblad, Olof Andersson, and Bo Liedberg. Photografted poly (ethylene glycol) matrix for affinity interaction studies. Biomacromolecules, 8(1):287-295, 2007.

[21] Javad Tavakoli and Youhong Tang. Hydrogel based sensors for biomedical applications: An updated review. Polymers, 9(8):364, 2017.

[22] André Laschewsky and Axel Rosenhahn. Molecular design of zwitterionic polymer interfaces: Searching for the difference. Langmuir, 2018.

[23] Qing Shao and Shaoyi Jiang. Molecular understanding and design of zwitterionic materials. Advanced Materials, 27(1):15-26, 2015.

[24] Jacob Baggerman, Maarten M J Smulders, and Han Zuilhof. Romantic surfaces: A systematic overview of stable, biospecific, and antifouling zwitterionic surfaces. Langmuir, 35(5):1072-1084, 2019. 
[25] Lewis D Blackman, Pathiraja A Gunatillake, Peter Cass, and Katherine E S Locock. An introduction to zwitterionic polymer behavior and applications in solution and at surfaces. Chemical Society Reviews, 2019.

[26] J Milton Harris. Poly (ethylene glycol) chemistry: Biotechnical and biomedical applications. Springer Science \& Business Media, 2013.

[27] Katrin Knop, Richard Hoogenboom, Dagmar Fischer, and Ulrich S Schubert. Poly (ethylene glycol) in drug delivery: Pros and cons as well as potential alternatives. Angewandte Chemie International Edition, 49(36):6288-6308, 2010 .

[28] Susanne Schöttler, Greta Becker, Svenja Winzen, Tobias Steinbach, Kristin Mohr, Katharina Landfester, Volker Mailänder, and Frederik R Wurm. Protein adsorption is required for stealth effect of poly (ethylene glycol)-and poly (phosphoester)-coated nanocarriers. Nature Nanotechnology, 11(4):372, 2016.

[29] Beatriz Pelaz, Pablo del Pino, Pauline Maffre, Raimo Hartmann, Marta Gallego, Sara Rivera-Fernandez, Jesus M de la Fuente, G Ulrich Nienhaus, and Wolfgang J Parak. Surface functionalization of nanoparticles with polyethylene glycol: Effects on protein adsorption and cellular uptake. ACS Nano, 9(7):6996-7008, 2015.

[30] Bryan Khai D Ngo and Melissa A Grunlan. Protein resistant polymeric biomaterials. ACS Macro Letters, 6(9):992-1000, 2017.

[31] Sitaraman Krishnan, Craig J Weinman, and Christopher K Ober. Advances in polymers for anti-biofouling surfaces. Journal of Materials Chemistry, 18(29):3405-3413, 2008.

[32] Xiaowu Fan, Lijun Lin, and Phillip B Messersmith. Cell fouling resistance of polymer brushes grafted from Ti substrates by surface-initiated polymerization: Effect of ethylene glycol side chain length. Biomacromolecules, $7(8): 2443-2448,2006$.

[33] Qi Yang, Stephen W Jones, Christina L Parker, William C Zamboni, James E Bear, and Samuel K Lai. Evading immune cell uptake and clearance requires PEG grafting at densities substantially exceeding the minimum for brush conformation. Molecular Pharmaceutics, 11(4):1250-1258, 2014.

[34] Peter L Turecek, Mary J Bossard, Freddy Schoetens, and Inge A Ivens. PEGylation of biopharmaceuticals: A review of chemistry and nonclinical safety information of approved drugs. Journal of Pharmaceutical Sciences, 105(2):460-475, 2016.

[35] Qingguo Xu, Laura M. Ensign, Nicholas J. Boylan, Arne Schön, Xiaoqun Gong, Jeh-Chang Yang, Nicholas W. Lamb, Shutian Cai, Tao Yu, Ernesto Freire, and Justin Hanes. Impact of surface polyethylene glycol (PEG) density on biodegradable nanoparticle transport in mucus ex vivo and distribution in vivo. ACS Nano, 9(9):9217-9227, 2015. 
[36] Hyungsoon Im, Huilin Shao, Yong Il Park, Vanessa M Peterson, Cesar M Castro, Ralph Weissleder, and Hakho Lee. Label-free detection and molecular profiling of exosomes with a nano-plasmonic sensor. Nature Biotechnology, 32(5):490, 2014.

[37] David M R Gibbs, Cameron R M Black, Jonathan I Dawson, and Richard $\mathrm{O} \mathrm{C}$ Oreffo. A review of hydrogel use in fracture healing and bone regeneration. Journal of Tissue Engineering and Regenerative Medicine, 10(3):187$198,2016$.

[38] Mei Liu, Xin Zeng, Chao Ma, Huan Yi, Zeeshan Ali, Xianbo Mou, Song $\mathrm{Li}$, Yan Deng, and Nongyue He. Injectable hydrogels for cartilage and bone tissue engineering. Bone Research, 5:17014, 2017.

[39] Olof Andersson, Andréas Larsson, Tobias Ekblad, and Bo Liedberg. Gradient hydrogel matrix for microarray and biosensor applications: An imaging SPR study. Biomacromolecules, 10(1):142-148, 2008.

[40] Lars Faxälv, Tobias Ekblad, Bo Liedberg, and Tomas L Lindahl. Blood compatibility of photografted hydrogel coatings. Acta Biomaterialia, 6(7):2599$2608,2010$.

[41] Zheng Zhang, Shengfu Chen, Yung Chang, and Shaoyi Jiang. Surface grafted sulfobetaine polymers via atom transfer radical polymerization as superlow fouling coatings. The Journal of Physical Chemistry B, 110(22):10799-10804, 2006 .

[42] Darren W Branch, Bruce C Wheeler, Gregory J Brewer, and Deborah E Leckband. Long-term stability of grafted polyethylene glycol surfaces for use with microstamped substrates in neuronal cell culture. Biomaterials, 22(10):1035-1047, 2001.

[43] Rupert Konradi, Bidhari Pidhatika, Andreas Mühlebach, and Marcus Textor. Poly-2-methyl-2-oxazoline: a peptide-like polymer for protein-repellent surfaces. Langmuir, 24(3):613-616, 2008.

[44] Enas M Ahmed. Hydrogel: Preparation, characterization, and applications: A review. Journal of Advanced Research, 6(2):105-121, 2015.

[45] Kenichi Nagase and Teruo Okano. Thermoresponsive-polymer-based materials for temperature-modulated bioanalysis and bioseparations. Journal of Materials Chemistry B, 4(39):6381-6397, 2016.

[46] Tobias Ekblad. Hydrogel coatings for biomedical and biofouling applications. $\mathrm{PhD}$ thesis, Linköping University Electronic Press, 2010.

[47] Bo Liedberg, Ingemar Lundström, and Esa Stenberg. Principles of biosensing with an extended coupling matrix and surface plasmon resonance. Sensors and Actuators B: Chemical, 11(1-3):63-72, 1993. 
[48] Judith McCann, Jonathan M Behrendt, Junfeng Yan, Silvia Halacheva, and Brian R Saunders. Poly (vinylamine) microgel-dextran composite hydrogels: Characterisation; properties and pH-triggered degradation. Journal of Colloid and Interface Science, 449:21-30, 2015.

[49] Surangkhana Martwiset, Anna E Koh, and Wei Chen. Nonfouling characteristics of dextran-containing surfaces. Langmuir, 22(19):8192-8196, 2006.

[50] Qingsheng Liu and Lingyun Liu. Novel light-responsive hydrogels with antimicrobial and antifouling capabilities. Langmuir, 2018.

[51] Ying-Nien Chou, Fang Sun, Hsiang-Chieh Hung, Priyesh Jain, Andrew Sinclair, Peng Zhang, Tao Bai, Yung Chang, Ten-Chin Wen, Qiuming Yu, and Shaoyi Jiang. Ultra-low fouling and high antibody loading zwitterionic hydrogel coatings for sensing and detection in complex media. Acta Biomaterialia, 40:31-37, 2016.

[52] Lily D Chambers, Keith R Stokes, Frank C Walsh, and Robert J K Wood. Modern approaches to marine antifouling coatings. Surface and Coatings Technology, 201(6):3642-3652, 2006.

[53] Ayda G. Nurioglu, A. Catarina C. Esteves, and Gijsbertus de With. Nontoxic, non-biocide-release antifouling coatings based on molecular structure design for marine applications. Journal of Materials Chemistry B, 3(32):6547-6570, 2015.

[54] Rosaria Ciriminna, Frank V Bright, and Mario Pagliaro. Ecofriendly antifouling marine coatings. ACS Sustainable Chemistry 85 Engineering, 3(4):559-565, 2015.

[55] Laiyong Xie, Fei Hong, Chuanxin He, Chunfeng Ma, Jianhong Liu, Guangzhao Zhang, and Chi Wu. Coatings with a self-generating hydrogel surface for antifouling. Polymer, 52(17):3738-3744, 2011.

[56] Maria Lagerström, J Fredrik Lindgren, Albin Holmqvist, Mia Dahlström, and Erik Ytreberg. In situ release rates of $\mathrm{Cu}$ and $\mathrm{Zn}$ from commercial antifouling paints at different salinities. Marine Pollution Bulletin, 127:289$296,2018$.

[57] William A Rutala and David J Weber. Disinfection, sterilization, and antisepsis: An overview. American Journal of Infection Control, 44(5):e1-e6, 2016.

[58] Craig A Wallace. New developments in disinfection and sterilization. American Journal of Infection Control, 44(5):e23-e27, 2016.

[59] Tiphaine Mérian and Julie M Goddard. Advances in nonfouling materials: Perspectives for the food industry. Journal of Agricultural and Food Chemistry, 60(12):2943-2957, 2012.

[60] Shengfu Chen and Shaoyi Jiang. An new avenue to nonfouling materials. Advanced Materials, 20(2):335-338, 2008. 
[61] Mojtaba Binazadeh, Maryam Kabiri, and Larry D Unsworth. Poly (ethylene glycol) and poly (carboxy betaine) based nonfouling architectures: Review and current efforts. In Proteins at Interfaces III State of the Art, ACS Symposium Series, volume 1120, pages 621-643. American Chemical Society, 2012 .

[62] Shengfu Chen, Fuchen Yu, Qiuming Yu, Yi He, and Shaoyi Jiang. Strong resistance of a thin crystalline layer of balanced charged groups to protein adsorption. Langmuir, 22(19):8186-8191, 2006.

[63] Stella Bauer, Maria Alles, John A Finlay, James A Callow, Maureen E Callow, and Axel Rosenhahn. Influence of zwitterionic SAMs on protein adsorption and the attachment of algal cells. Journal of Biomaterials Science, Polymer Edition, 25(14-15):1530-1539, 2014.

[64] Shenfu Chen, Lingyan Li, Chao Zhao, and Jie Zheng. Surface hydration: Principles and applications toward low-fouling/nonfouling biomaterials. Polymer, 51(23):5283-5293, 2010.

[65] Chuan Leng, Hsiang-Chieh Hung, Shuwen Sun, Dayang Wang, Yuting Li, Shaoyi Jiang, and Zhan Chen. Probing the surface hydration of nonfouling zwitterionic and PEG materials in contact with proteins. ACS Applied Materials \& Interfaces, 7(30):16881-16888, 2015.

[66] R Erik Holmlin, Xiaoxi Chen, Robert G Chapman, Shuichi Takayama, and George M Whitesides. Zwitterionic SAMs that resist nonspecific adsorption of protein from aqueous buffer. Langmuir, 17(9):2841-2850, 2001.

[67] Jian-Ping Deng, Wan-Tai Yang, and Bengt Rånby. Auto-initiating performance of styrene on surface photografting polymerization. Macromolecular Rapid Communications, 22(7):535-538, 2001.

[68] Huiliang Wang and Hugh R Brown. Self-initiated photopolymerization and photografting of acrylic monomers. Macromolecular Rapid Communications, 25(11):1095-1099, 2004.

[69] Pierre-Gilles De Gennes. Scaling concepts in polymer physics. Cornell university press, 1979.

[70] Tommie W Kelley, Phillip A Schorr, Kristin D Johnson, Matthew Tirrell, and C Daniel Frisbie. Direct force measurements at polymer brush surfaces by atomic force microscopy. Macromolecules, 31(13):4297-4300, 1998.

[71] T Abraham, S Giasson, Jean-François Gohy, and Robert Jérôme. Direct measurements of interactions between hydrophobically anchored strongly charged polyelectrolyte brushes. Langmuir, 16(9):4286-4292, 2000.

[72] Scott T Milner, T A Witten, and M E Cates. Theory of the grafted polymer brush. Macromolecules, 21(8):2610-2619, 1988. 
Bibliography

[73] R Israels, F A M Leermakers, G J Fleer, and E B Zhulina. Charged polymeric brushes: Structure and scaling relations. Macromolecules, 27(12):3249-3261, 1994.

[74] S Michael Kilbey II and John F Ankner. Neutron reflectivity as a tool to understand polyelectrolyte brushes. Current Opinion in Colloid $\mathscr{E}$ Interface Science, 17(2):83-89, 2012.

[75] Krzysztof Matyjaszewski and Jianhui Xia. Atom transfer radical polymerization. Chemical Reviews, 101(9):2921-2990, 2001.

[76] S Alexander. Adsorption of chain molecules with a polar head a scaling description. Journal De Physique, 38(8):983-987, 1977.

[77] P G de Gennes. Conformations of polymers attached to an interface. Macromolecules, 13(5):1069-1075, 1980.

[78] Iain E Dunlop, Wuge H Briscoe, Simon Titmuss, Robert M J Jacobs, Vicky L Osborne, Steve Edmondson, Wilhelm T S Huck, and Jacob Klein. Direct measurement of normal and shear forces between surface-grown polyelectrolyte layers. The Journal of Physical Chemistry B, 113(12):3947-3956, 2009 .

[79] Thomas Ederth and Tobias Ekblad. Swelling of thin poly (ethylene glycol)containing hydrogel films in water vapor-A neutron reflectivity study. Langmuir, 34(19):5517-5526, 2018.

[80] Cristian Mendes-Felipe, Juliana Oliveira, Ikerne Etxebarria, José Luis VilasVilela, and Senentxu Lanceros-Mendez. State-of-the-Art and future challenges of UV curable polymer-based smart materials for printing technologies. Advanced Materials Technologies, page 1800618, 2019.

[81] Yusuf Wibisono, Wetra Yandi, Mohsen Golabi, Roni Nugraha, Emile R Cornelissen, Antoine J B Kemperman, Thomas Ederth, and Kitty Nijmeijer. Hydrogel-coated feed spacers in two-phase flow cleaning in spiral wound membrane elements: A novel platform for eco-friendly biofouling mitigation. Water Research, 71:171-186, 2015.

[82] Jing Zhang and Nicholas A Peppas. Synthesis and characterization of ph-and temperature-sensitive poly (methacrylic acid)/poly (n-isopropylacrylamide) interpenetrating polymeric networks. Macromolecules, 33(1):102-107, 2000.

[83] Peter Larkin. Infrared and Raman spectroscopy: principles and spectral interpretation. Elsevier, 2017.

[84] Friedrich M Hoffmann. Infrared reflection-absorption spectroscopy of adsorbed molecules. Surface Science Reports, 3(2-3):107-192, 1983.

[85] Andreas Barth. Infrared spectroscopy of proteins. Biochimica et Biophysica Acta (BBA)-Bioenergetics, 1767(9):1073-1101, 2007. 
[86] Ernst Meyer, Hans Josef Hug, and Roland Bennewitz. Scanning probe microscopy: The lab on a tip. Springer Science \& Business Media, 2013.

[87] William A Ducker, Tim J Senden, and Richard M Pashley. Direct measurement of colloidal forces using an atomic force microscope. Nature, 353(6341):239, 1991.

[88] Gil U Lee, David A Kidwell, and Richard J Colton. Sensing discrete streptavidin-biotin interactions with atomic force microscopy. Langmuir, 10(2):354-357, 1994.

[89] Thorsten Hugel and Markus Seitz. The study of molecular interactions by AFM force spectroscopy. Macromolecular Rapid Communications, 22(13):989-1016, 2001.

[90] Ulrich Dammer, Martin Hegner, Dario Anselmetti, Peter Wagner, Markus Dreier, Walter Huber, and Hans-Joachim Güntherodt. Specific antigen/antibody interactions measured by force microscopy. Biophysical Journal, 70(5):2437-2441, 1996.

[91] Harland Tompkins and Eugene A Irene. Handbook of ellipsometry. William Andrew, 2005.

[92] Ivan D Nikolov and Christo D Ivanov. Optical plastic refractive measurements in the visible and the near-infrared regions. Applied Optics, 39(13):2067-2070, 2000.

[93] Olof Sterner. Swelling and protein adsorption characteristics of stimuliresponsive hydrogel gradients, 2010.

[94] Olof Andersson. Imaging Surface plasmon resonance. PhD thesis, Linköping University Electronic Press, 2008.

[95] E Dulkeith, A C Morteani, T Niedereichholz, T A Klar, J Feldmann, S A Levi, F C J M Van Veggel, D N Reinhoudt, M Möller, and D I Gittins. Fluorescence quenching of dye molecules near gold nanoparticles: Radiative and nonradiative effects. Physical Review Letters, 89(20):203002, 2002.

[96] Guillermo P. Acuna, Martina Bucher, Ingo H. Stein, Christian Steinhauer, Anton Kuzyk, Phil Holzmeister, Robert Schreiber, Alexander Moroz, Fernando D. Stefani, Tim Liedl, Friedrich C. Simmel, and Philip Tinnefeld. Distance dependence of single-fluorophore quenching by gold nanoparticles studied on DNA origami. ACS Nano, 6(4):3189-3195, 2012.

[97] Chris D Geddes and Joseph R Lakowicz. Metal-Enhanced Fluorescence. Journal of Fluorescence, 12(2):121-129, 2002.

[98] Joseph I Goldstein, Dale E Newbury, Joseph R Michael, Nicholas W M Ritchie, John Henry J Scott, and David C Joy. Scanning electron microscopy and X-ray microanalysis. Springer, 2017. 
Bibliography

[99] Athene M Donald. The use of environmental scanning electron microscopy for imaging wet and insulating materials. Nature Materials, 2(8):511, 2003.

[100] Jacob N Israelachvili. Intermolecular and surface forces. Academic press, 2011.

[101] Jean-Marie Lehn. Supramolecular chemistry-scope and perspectives molecules, supermolecules, and molecular devices (Nobel Lecture). Angewandte Chemie International Edition, 27(1):89-112, 1988.

[102] H C Hamaker. The London - van der Waals attraction between spherical particles. Physica, 4(10):1058-1072, 1937.

[103] David C Grahame. The electrical double layer and the theory of electrocapillarity. Chemical Reviews, 41(3):441-501, 1947.

[104] Evert Johannes Willem Verwey. Theory of the stability of lyophobic colloids. The Journal of Physical Chemistry, 51(3):631-636, 1947.

[105] B Derjaguin and L Landau. Theory of the stability of strongly charged lyophobic sols and of the adhesion of strongly charged particles in solutions of electrolytes. Progress in Surface Science, 43(1-4):30-59, 1993.

[106] Jacob N Israelachvili and Haakan Wennerstroem. Entropic forces between amphiphilic surfaces in liquids. The Journal of Physical Chemistry, 96(2):520-531, 1992.

[107] Hans-Jürgen Butt. Measuring electrostatic, van der Waals, and hydration forces in electrolyte solutions with an atomic force microscope. Biophysical Journal, 60(6):1438-1444, 1991.

[108] David Chandler. Interfaces and the driving force of hydrophobic assembly. Nature, 437(7059):640, 2005.

[109] Emily E Meyer, Kenneth J Rosenberg, and Jacob Israelachvili. Recent progress in understanding hydrophobic interactions. Proceedings of the $\mathrm{Na}$ tional Academy of Sciences, 103(43):15739-15746, 2006.

[110] Andrew D Levin, Neda Vukmirovic, Chao-Wei Hwang, and Elazer R Edelman. Specific binding to intracellular proteins determines arterial transport properties for rapamycin and paclitaxel. Proceedings of the National Academy of Sciences, 101(25):9463-9467, 2004.

[111] Yoichiro Kamiyama and Jacob Israelachvili. Effect of $\mathrm{pH}$ and salt on the adsorption and interactions of an amphoteric polyelectrolyte. Macromolecules, 25(19):5081-5088, 1992.

[112] Kenneth Langstreth Johnson, Kevin Kendall, and A D Roberts. Surface energy and the contact of elastic solids. Proceedings of the Royal Society of London. A. Mathematical and Physical Sciences, 324(1558):301-313, 1971. 
[113] Boris V Derjaguin, Vladimir M Muller, and Yu P Toporov. Effect of contact deformations on the adhesion of particles. Journal of Colloid and Interface Science, 53(2):314-326, 1975.

[114] V M Muller, B V Derjaguin, and Yu P Toporov. On two methods of calculation of the force of sticking of an elastic sphere to a rigid plane. Colloids and Surfaces, 7(3):251-259, 1983.

[115] Stefan Alexander Maier. Plasmonics: Fundamentals and applications. Springer Science \& Business Media, 2007.

[116] K H Drexhage. Influence of a dielectric interface on fluorescence decay time. Journal of Luminescence, 1:693-701, 1970.

[117] Matthew E Stewart, Christopher R Anderton, Lucas B Thompson, Joana Maria, Stephen K Gray, John A Rogers, and Ralph G Nuzzo. Nanostructured plasmonic sensors. Chemical Reviews, 108(2):494-521, 2008.

[118] Jian Zhang and Joseph R Lakowicz. Metal-Enhanced Fluorescence of an organic fluorophore using gold particles. Optics Express, 15(5):2598-2606, 2007 .

[119] Bingjie Yang, Nan Lu, Dianpeng Qi, Renping Ma, Qiong Wu, Juanyuan Hao, Xiaoming Liu, Ying Mu, Vincent Reboud, Nikolaos Kehagias, Clivia M. Sotomayor Torres, Freddy Yin Chiang Boey, Xiaodong Chen, and Lifeng Chi. Tuning the intensity of Metal-Enhanced Fluorescence by engineering silver nanoparticle arrays. Small, 6(9):1038-1043, 2010.

[120] S Derom, A Berthelot, A Pillonnet, O Benamara, A M Jurdyc, C Girard, and G Colas des Francs. Metal Enhanced Fluorescence in rare earth doped plasmonic core-shell nanoparticles. Nanotechnology, 24(49):495704, 2013.

[121] Philipp Reineck, Daniel Gómez, Soon Hock Ng, Matthias Karg, Toby Bell, Paul Mulvaney, and Udo Bach. Distance and wavelength dependent quenching of molecular fluorescence by $\mathrm{Au} @ \mathrm{SiO}_{2}$ core-shell nanoparticles. ACS Nano, 7(8):6636-6648, 2013.

[122] H Mertens and A Polman. Plasmon-enhanced erbium luminescence. Applied Physics Letters, 89(21):211107, 2006.

[123] Joseph R Lakowicz. Radiative decay engineering 5: Metal-Enhanced Fluorescence and plasmon emission. Analytical Biochemistry, 337(2):171-194, 2005 .

[124] Yongxia Zhang, Anatoliy Dragan, and Chris D Geddes. Wavelength dependence of Metal-Enhanced Fluorescence. The Journal of Physical Chemistry C, 113(28):12095-12100, 2009.

[125] Katherine A Willets and Richard P Van Duyne. Localized surface plasmon resonance spectroscopy and sensing. Annual Review of Physical Chemistry, 58:267-297, 2007. 
[126] Yoon Jeong, Yun-Min Kook, Kangwon Lee, and Won-Gun Koh. Metal Enhanced Fluorescence (MEF) for biosensors: General approaches and a review of recent developments. Biosensors and Bioelectronics, 2018.

[127] Krishanu Ray, Ramachandram Badugu, and Joseph R Lakowicz. Distancedependent Metal-Enhanced Fluorescence from Langmuir- Blodgett monolayers of Alkyl-NBD derivatives on silver island films. Langmuir, 22(20):8374$8378,2006$.

[128] Daming Cheng and Qing-Hua Xu. Separation distance dependent fluorescence enhancement of fluorescein isothiocyanate by silver nanoparticles. Chemical Communications, (3):248-250, 2007.

[129] Subhasish Chatterjee, Jong Bum Lee, Nikesh V Valappil, Dan Luo, and Vinod M Menon. Investigating the distance limit of a metal nanoparticle based spectroscopic ruler. Biomedical Optics Express, 2(6):1727-1733, 2011.

[130] Nardine S Abadeer, Marshall R Brennan, William L Wilson, and Catherine J Murphy. Distance and plasmon wavelength dependent fluorescence of molecules bound to silica-coated gold nanorods. ACS Nano, 8(8):8392-8406, 2014.

[131] Tânia Ribeiro, Carlos Baleizão, and José Paulo S Farinha. Artefact-free evaluation of Metal Enhanced Fluorescence in silica coated gold nanoparticles. Scientific Reports, 7(1):2440, 2017. 


\section{Papers}

The papers associated with this thesis have been removed for copyright reasons. For more details about these see:

http://urn.kb.se/resolve?urn=urn:nbn:se:liu:diva-156496 


\section{FACULTY OF SCIENCE AND ENGINEERING}

Linköping Studies in Science and Technology, Dissertation No. 1987, 2019 Department of Physics, Chemistry and Biology

Linköping University

SE-581 83 Linköping, Sweden

www.liu.se 